
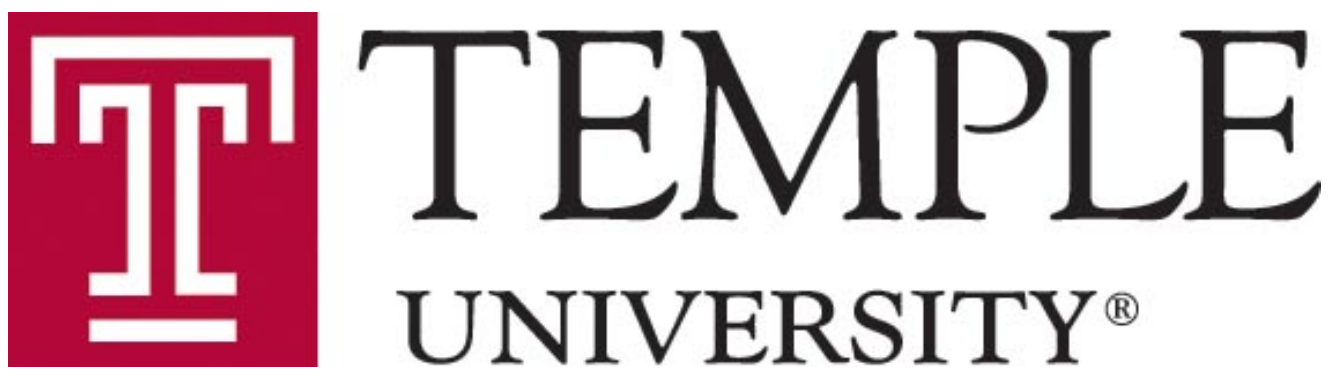

Social Insurance and Occupational Mobility

\author{
German Cubas \\ Department of Economics \\ University of Houston \\ Pedro Silos \\ Department of Economics \\ Temple University
}

Department of Economics

DETU Working Paper 18-02

February 2018

1301 Cecil B. Moore Avenue, Philadelphia, PA 19122

http://www.cla.temple.edu/economics/faculty/detu-working-paper-series/ 


\title{
Social Insurance and Occupational Mobility
}

\author{
German Cubas and Pedro Silos*
}

February, 2018

\begin{abstract}
This paper studies how insurance from progressive taxation improves the matching of workers to occupations. We propose an equilibrium dynamic assignment model to illustrate how social insurance encourages mobility. Workers experiment to find their best occupational fit in a process filled with uncertainty. Risk aversion and limited earnings insurance induce workers to remain in unfitting occupations. We estimate the model using microdata from the United States and Germany. Higher earnings uncertainty explains the U.S. higher mobility rate. When workers in the United States enjoy Germany's higher progressivity, mobility rises. Output and welfare gains are large.
\end{abstract}

Key words: Progressive Taxation, Social Insurance, Occupational Choice JEL Classifications: E21 $\cdot \mathrm{H} 24 \cdot \mathrm{J} 31$.

\footnotetext{
*Affiliations: University of Houston, Temple University, respectively. Corresponding author: Pedro Silos, Temple University, Ritter Annex 8791303 Cecil B. Moore Ave, Philadelphia, PA 19122, USA, pedro.silos@temple.edu. We thank L. Ales, A. Bick, M. Bils, Y. Chang, S. Chatterjee, M. De Nardi, A. Drenik, M. Dvorkin, L. Hendricks, R. Hosseini, G. Kambourov, G. Kaplan, A. Michaud, S. Pashchenko, B. Ravikumar, A. Seshadri, B. Sorensen, V. Ríos-Rull, R. Rogerson, R. Serrano-Padial, Y. Shin, G. Ventura, and G. Vereshchagina, for their comments and suggestions. Seminar participants at Arizona State University, Central Bank of Uruguay, Center for Research and Teaching in Economics (CIDE), Federal Reserve Bank of Kansas City, George Washington University, Iecon-Udelar, SAIS-John Hopkins University, Society for Economic Dynamics Meeting in Edinburgh, University of Chile, University of Cincinnati, University of Georgia , University of Iowa, and Virginia Commonwealth University provided useful feedback. This research was supported in part by the National Science Foundation through major research instrumentation grant number CNS-09-58854. Earlier versions of this paper circulated under the name "Risk Taking to Succeed: Progressive Taxation and Risky Career Choices".
} 


\section{Introduction}

Can redistributive taxation increase aggregate output by encouraging occupational mobility? According to conventional wisdom the answer is no. Continental Europe, with its high levels of redistribution and low job and occupational mobility rates, is presented as a case in point. In this paper, we argue instead that redistributive taxation encourages occupational mobility. The better assignment of workers to occupations that follows results in higher productivity and output. To arrive at that answer, we link two seemingly unrelated areas of work. One highlights the role of job and occupational mobility in producing better matches, and as a result, higher productivity and earnings. ${ }^{1}$ The other, studies the welfare effects of social insurance policies, particularly, progressive taxation. These policies are designed to shield workers from adverse earnings shocks and reduce inequality. It is the insurance provided to risk averse workers by the tax system that leads to a higher occupational mobility rate when redistribution rises. We also demonstrate that the source of the low occupational mobility rate in Germany-representative of Continental Europe -is the much lower frequency of large shocks to earnings experienced by German workers.

The central argument of this paper is as follows. The process of finding the best occupation requires experimentation by workers. Few ever have perfect information about their abilities and, as a result, about the likelihood of success in every available occupation. To overcome this obstacle they try alternative professions, settling for one when the gain in a prospective occupation is not worth the risk. ${ }^{2}$ Even when workers know their abilities, they may change occupations in response to shifts in earnings prospects in alternative occupations, a common aspect of labor markets. ${ }^{3}$ If opportunities to insure earnings risk are limited and workers are risk-averse, they may settle for an unfit occupation, forgoing opportunities that the labor market offers. Therefore, lack of insurance is a source of worker misallocation. By partially filling in for missing private insurance markets, social insurance

\footnotetext{
${ }^{1}$ Early references for this line of work are Jovanovic (1979), Miller (1984), and Topel and Ward (1992).

${ }^{2}$ These ideas are central to Miller (1984) and countless references after his work.

${ }^{3}$ Kambourov and Manovskii (2009) emphasize the role of occupation-specific shocks to earnings.
} 
programs - for example, progressive or redistributive taxation-favor risk-taking and encourage mobility. ${ }^{4}$ As a result, such programs improve the sorting of workers into occupations, thus raising output and welfare.

The mechanism we highlight has not been explored, let alone quantified, in a vast literature on macroeconomics and public finance in which the central question is the design of tax and transfer schemes. We fill this gap by linking the two areas of the literature described earlier. In doing so, we make empirical, theoretical, and quantitative contributions. On the empirical side we uncover new features of the U.S. and German labor markets. On the theoretical side we build an equilibrium ability-to-occupation assignment model (Roy, 1951) with missing insurance markets. Our framework allows analysis of the interaction of occupational choice, earnings risk, and social insurance. ${ }^{5}$ On the quantitative side, we take our theoretical framework to the data and quantify the output and welfare of different policies. Our analysis focuses on one type of social insurance policy: progressive taxation. ${ }^{6}$

We begin by documenting new facts about earnings risk and occupational mobility for the United States and Germany. We focus our analysis on these two countries because of the substantial differences in their tax systems (see Holter, Krueger, and Stepanchuk, 2015). The German tax system is more progressive than that of the United States. ${ }^{7}$ We find that, first, the U.S. labor market is much riskier-earnings are more uncertain — than the German labor market. We estimate the standard deviation of permanent shocks to earnings in both countries and find that on average it is $40 \%$ higher in the United States. ${ }^{8}$ Second, there is substantial variation in earnings risk across occupations in both countries. In the Unite States, sales workers

\footnotetext{
${ }^{4}$ The idea that redistributive taxation makes uncertainty more attractive for risk-averse individuals goes back to Mirrlees (1974), Eaton and Rosen (1980a), Eaton and Rosen (1980b), and Varian (1980).

5Throughout the paper the terms "risk" and "uncertainty" are used interchangeably.

${ }^{6} \mathrm{We}$ do not consider the intensive margin of the labor supply as well as savings, and thus we abstract from some of the negative effect of progressivity. Our goal is to quantify how much progressivity improves the matching of workers to occupations. We show that the effects on output and welfare are large.

${ }^{7} \mathrm{~A}$ second reason is that we have comparable longitudinal microdata available.

${ }^{8}$ Note that these are permanent shocks, so even small differences in the standard deviation of earnings can translate into large changes in utility.
} 
experience large permanent shocks to earnings, whereas administrative workers do not. In Germany, the riskiest occupation is being a manager and the safest is being a clerical worker. ${ }^{9}$ Third, occupational mobility—the rate at which workers change occupations-is substantially lower in Germany. The 2-year mobility rate in the United States is about $25 \%$, but it is only 3.7\% in Germany. At face value, this fact may seem to invalidate our hypothesis: that Germany's more generous social insurance programs encourage mobility. Yet, it is possible that differences in risk across the two economies partly explain the disparity in occupational mobility. ${ }^{10}$ To isolate the importance of earnings risk for occupational mobility, we use a logit model to estimate the likelihood of a worker switching occupations when faced with an unpredictable drop in earnings. That likelihood, which we label the propensity to switch, is similar for German and U.S. workers. This finding suggests that U.S. workers change occupations more frequently as a natural response to the larger shocks they face compared with German workers.

Our theoretical contribution is to develop a life-cycle model incorporating the interaction among earnings risk, social insurance, and occupational mobility. Every period, a worker's decision is to pick between two options: remaining in the current occupation or switching to a more uncertain alternative. ${ }^{11}$ A worker's human capital comes in two varieties. The first variety is an occupation-specific innate ability that is discovered sequentially. The second variety is a general- transferable across occupations-level of human capital. As workers' careers progress, more information is revealed about their innate abilities; experience reduces labor market uncertainty. However, workers experience occupation-specific permanent shocks to their general human capital. For workers, a prospective occupation is

\footnotetext{
${ }^{9}$ The standard deviations of permanent shocks, exogenous in our analysis, reflect many differences in the labor markets in these countries. For example, regulations and institutions such as collective bargaining make hours and wage adjustments less frequent in Germany compared with the United States (e.g. the retail sector for sales workers is much more regulated in Germany).

${ }^{10}$ There are other aspects of these countries that surely affect the mobility of workers. An example is the vocational educational system in Germany. Our model does not incorporate many of the institutional differences. We opt instead to have an age-dependent mobility cost function whose role in the model is to capture these institutional differences.

${ }^{11}$ This trade-off between "exploiting" a current occupation and "experimenting" with an alternative is typical of multi-armed bandit problems. Miller (1984), Papageorgiou (2014), and Silos and Smith (2015) are examples of the same trade-off in models of occupational choice.
} 
always more uncertain than their current occupation. The insurance provided by progressive taxes increases the relative value of uncertainty. The reason is that workers dislike risk, and progressive taxes redistribute from high to low earnings realizations. As a result, under a more progressive tax, a worker sees a lower probability of a low-earnings outcome. Of course, he also sees a lower probability of a high outcome, but that is the purpose of insurance. Because he is risk-averse, the worker accepts the trade-off: the lower likelihood of low earnings more than compensates, in utility terms, the lower likelihood of high earnings. This effect is larger the riskier an occupation is. In other words, the increase in the relative value of a risky occupation is greater than that of a safe occupation. Risky occupations become relatively more attractive.

In the model, labor markets-one for each occupation-are competitive. The price of a unit of efficiency clears the market for a given occupation. The demand for that occupation is driven by a technology employing all occupations and used to produce a general consumption good. The supply is driven by the selection of workers into that occupation based on their individual job histories. Despite the higher relative value of risky occupations, it is not inevitable that the size of risky occupations increases after a more progressive tax is introduced. The result is a combination of two effects. First, a more progressive tax function increases the number of inflows to riskier occupations. But because those occupations are risky - earnings shocks are large — the number of outflows also increases. Second, as workers flow into risky occupations, the equilibrium price of an efficiency unit falls, making that occupation relatively less attractive.

We calibrate the model to the United States and Germany using our estimates of permanent earnings risk as well as data on occupational mobility. We then ask, how much does social insurance matter for output and welfare? To answer that question, we assign the more progressive German tax system to the United States and find that occupation mobility increases as workers are willing to assume more 
risk. ${ }^{12}$ The higher rate of mobility increases output by $4 \% .{ }^{13}$ To understand our results, note that the decision of switching occupations rule always takes the form of a productivity cutoff below which the worker stays in the current occupation. Productivity is the result of abilities and general human capital, so realizations of the first or shocks to the second (or both) may prompt a switch. By making switches more attractive, progressivity raises the productivity cutoff. As a result, a marginal worker-who is indifferent between switching or staying-is more productive. Productivity per worker rises and so does aggregate output. To investigate the welfare effects of such a policy change, we compute the consumption equivalent variation (CEV). Welfare rises by $2.6 \%$ of annual consumption. Both the higher output and the smoother earnings-consequences of the extra insuranceunderlie the rise in welfare. ${ }^{14}$ The calibrated model also allows us to isolate the effect of the extra insurance on workers' mobility decisions. To that end, we calculate workers' propensity to switch occupations using simulated data from the baseline and the counterfactual economies. The propensity to switch increases by $18 \%$ when U.S. workers enjoy the insurance of the German tax system.

As in the empirical section, we examine whether the more volatile U.S. labor market is responsible for a higher occupational mobility rate. ${ }^{15}$ For that purpose, we force U.S. workers to face the earnings risk of Germany. Mobility drops by 13 percentage points, and because the potential for high outcomes is lower, aggregate

\footnotetext{
${ }^{12}$ The tax functions for the U.S. and Germany that we employ are estimated in Holter, Krueger, and Stepanchuk (2015). This class of tax functions to summarize the income tax code were first proposed by Berliant and Gouveia (1993) and have been extensively used in the literature (see Conesa and Krueger (2006), Heathcote, Storesletten, and Violante (2014) and Guner, Kaygusuz, and Ventura (2014)). Although, one can consider a richer social insurance policy, this approach is appealing because: (i) it is tractable, (ii) it approximates closely and in a parsimonious way the income tax code, and (iii) the functional forms are flexible enough to incorporate a wide variety of transfer schemes.

${ }^{13}$ In this counterfactual we ensure that the average level of earnings taxes - measured by the ratio of tax revenues to output - remains the same. In other words, the effects we find are only due to higher progressivity and not to changes in the average level of taxes, which differ between Germany and the United States.

${ }^{14}$ In the same way, we perform the counterfactual exercise in which we give Germany the less progressive tax system of the United States. As expected, occupational mobility, output, and welfare, fall.

${ }^{15}$ That more risk leads to higher mobility appears to contradict our main message, which is that social insurance - which lowers earnings volatility - increases mobility. Note, however, that when one modifies the degree of tax progressivity, the underlying distribution of shocks remains the same. We further discuss this issue below, once we have presented our model results.
} 
output drops as well: by 39\%. Despite this drop in output, U.S. workers would rather live in this low-risk economy than in the benchmark. The benefits from the smoother earnings more than offset the losses from the lower mean earnings.

Related Literature: The paper connects four strands of the literature in macroeconomics and public finance. First, it relates to works studying the welfare effects of the social insurance from progressive income taxation. Our work is particularly related to the studies of Benabou (2002), Conesa and Krueger (2006), Conesa, Kitao, and Krueger (2009), and Seshadri and Yuki (2004). Following the work of Mirrlees (1974), Eaton and Rosen (1980a), Eaton and Rosen (1980b), and Varian (1980), those authors incorporate the effect of the insurance provided by progressive taxation into models with uninsurable idiosyncratic risk. Along the same line, Acemoglu and Shimer (1999) and Acemoglu and Shimer (2000) study the positive effect of unemployment insurance policies on the willingness of unemployed workers to accept low-productivity job offers. Another example is Golosov, Kocherlakota, and Tsyvinski (2003), who also incorporate idiosyncratic income shocks and private information to study the optimality of capital taxation. Since we study the assignment of heterogeneous workers to occupations, our work is also related to studies of optimal taxation using task-to-talent assignment models. Examples are Rothschild and Scheuer (2013) and Ales, Kurnaz, and Sleet (2015) who study optimal taxation in static models when the talent of individuals is private information.

Our paper distinguishes itself in many dimensions. First, our focus is not normative. Rather, we take a more quantitative approach to measure the importance of earnings risk and social insurance in the career choices of individuals. As opposed to some of the assignment models discussed earlier (e.g. Ales, Kurnaz, and Sleet, 2015), our framework incorporates the dynamic nature of career progressions. There are important questions in public economics and macroeconomics that are inherently dynamic. For example, workers' skills change stochastically and have a life-cycle component. Another example is that shocks may not only affect earnings within the same occupation but also trigger occupational changes.

Our paper documents patterns of occupational mobility and analyze them in 
the context of an aggregate environment. We incorporate both new facts by comparing Germany and the United States and a new mechanism through which occupational mobility increases endogenously due to the earnings risk faced by workers. For these reasons, we see our work as complementing the work of Kambourov and Manovskii $(2008,2009)$. In addition, we incorporate the mechanisms present in Jovanovic (1979), Miller (1984), and Papageorgiou (2014). We complement their findings as well as the ones present in Cubas and Silos (2017), Silos and Smith (2015), Hawkins and Mustre del Rio (2012), Dillon (2017), and Neumuller (2015) by linking risk and abilities to the experimentation process. More importantly, by analyzing insurance policies in the context of a model of occupational choice with incomplete markets, we connect that literature to the work on public finance reviewed earlier.

Finally, our paper has implications for earnings inequality. Thus, it connects to other studies in macroeconomics concerned with the sources of lifetime inequality. Important such works are those by Keane and Wolpin (1997); Huggett, Ventura, and Yaron (2011); and Lee and Seshadri (2016). Although the human capital accumulation process is not as rich as in those papers, we incorporate the career choices of workers, which can be seen as part of their human capital accumulation process. In addition, in our framework the lack of missing private insurance markets greatly affects aggregate output and income inequality. For these reasons, our paper complements the findings of Benabou (2002), and Lee and Seshadri (2017). In our case, we find that most of the lifetime inequality is explained by the shocks to the general human capital that occur during a worker's career $(80 \%$ in the United States and 70\% in Germany). The remainder is due to differences in occupation-specific abilities (ex ante heterogeneity).

\section{Facts}

This paper studies how the interaction between earnings uncertainty and insurance opportunities determines workers' occupational choices. We begin by documenting new facts on occupational earnings risk and mobility for Germany and 
the United States. The reason for our focus on these two economies is twofold. First, they are the two largest economies for which high-quality harmonized panel data on earnings and occupations are available, for roughly the same time period. Second, even though they are both advanced economies, likely at the technological frontier, they provide quite different levels of social insurance.

\subsection{Data}

We use comparable cross-country longitudinal household surveys provided by the Cross-National Equivalent File (CNEF) at Ohio State University. The file contains consistently defined variables for a set of developed countries. Included in that data set are the U.S. Panel Study of Income Dynamics (PSID) and the German Socio-Economic Panel (SOEP).

The Panel Study of Income Dynamics In 1968 the PSID started collecting information on a sample of roughly 5,000 households. Of these, about 3,000 were representative of the U.S. population (the core sample) and about 2,000 were lowincome families (the Census Bureau's Survey of Economic Opportunity [SEO] sample). Thereafter, both the original families and their descendants (children of the original family forming a family of their own) have been followed. The panel is annual until 1997; it has since become biennial. In the empirical analysis we use the entire sample from 1980 through 2007 and adapt the estimation methodology to the change in the sampling frequency. ${ }^{16}$

The Socio-Economic Panel The SOEP data are drawn from the SOEP-CNEF files. The SOEP is a wide-ranging representative longitudinal study of private households, located at the German Institute for Economic Research, DIW Berlin. Every year nearly 15,000 households, and about 25,000 persons are sampled. The data provide information on all household members, consisting of Germans living in the old and new German states, foreigners, and recent immigrants to Germany. The panel started in 1984 and we use data up to 2012.

\footnotetext{
${ }^{16}$ The reason to start in 1980 is to have a approximately comparable sample period for Germany and the United States.
} 
For both countries, we restrict our sample to working-age individuals 26 to 60 years of age. We omit those who are not employed or who are self-employed, those who do not report earnings, education, or hours worked; as well as individuals with fewer than 8 years of consecutive data. In the PSID-CNEF, individuals are classified into occupations according to ISCO-68 and industries according to a 34-industry classification provided by the CNEF. ${ }^{17}$. The SOEP occupations are provided by using the ISCO-2008 (an update of ISCO-68) classification, so we convert them to the ISCO-68 by following the cross-walk provided by the ILO. After grouping the data into 12 occupations (see the appendix) the resulting data set is a panel of individuals' labor earnings per hour, employment status, age, education level, industry, occupation, and gender.

\subsection{Labor Income Shocks}

We use a regression approach extensively used in the literature (see, for instance, Carroll and Samwick, 1997) to compute earnings variability at the individual level. We estimate a fixed effects model for each occupation $j$ in our sample. Given a panel of $N$ individuals for whom we measure earnings per hour worked (and other variables) over a period of time $T$, we assume that (log) earnings per hour for individual $i$ in occupation $j$ at time $t, y_{i j t}$, can be written as:

$$
y_{i j t}=\alpha_{i j}+\boldsymbol{\beta}_{j} \boldsymbol{X}_{i j t}+u_{i j t}
$$

The vector $X$ includes observables that predict changes in the level of log earnings: age, gender, ethnicity, years of schooling, an industry dummy, and time dummies. $\beta_{j}$ are the corresponding coefficients, $\alpha_{i j}$ is the individual fixed effect, and $u_{i j t}$ the residual. We estimate equation (1) for all individuals in a given occupation. Repeating this procedure for all occupations yields estimates $\left\{\hat{\alpha}_{i j}, \hat{\boldsymbol{\beta}}_{j}\right\}_{j=1}^{12}$.

The nature of risk faced by workers is important for assessing the welfare consequences of changing social policies. Temporary shocks should not lead to major changes in workers' careers and are easily overcome by a small amount of savings.

\footnotetext{
${ }^{17}$ ISCO-68 refers to the first International Standard Classification of Occupations issued by the International Labor Organization (ILO).
} 
For that reason, we focus only on permanent (or very persistent) risk that can be associated with, for instance, a depreciation of occupation-specific human capital and can therefore lead to an occupational change. To decompose risk into a permanent component and a transitory component, we follow Carroll and Samwick (1997) and Low, Meghir, and Pistaferri (2010), among others. We assume that

$$
u_{i j t}=\eta_{i j t}+\omega_{i j t}
$$

where $\eta_{i j t}$, the transitory component, is distributed i.i.d. $N\left(0, \sigma_{\eta j}^{2}\right)$ and $\omega_{i j t}$, the permanent component, follow a random walk,

$$
\omega_{i j t}=\omega_{i j, t-1}+\epsilon_{i j t}
$$

with i.i.d. innovations $\epsilon_{i j t}$ that are distributed $N\left(0, \sigma_{\epsilon j}^{2}\right)$. By estimating equation (1), we obtain $\left\{\left\{\hat{u}_{i j t}\right\}_{i=1}^{N_{j}}\right\}_{t=1}^{T}$.

Our procedure to estimate the variances of $\epsilon$ and $\eta$ follows Low, Meghir, and Pistaferri (2010). Given that the PSID is biennial after 1997, we take second differences in equation (10). Using (2), we have

$$
\Delta_{2} y_{i j t}=y_{i j t}-y_{i j t-2}=\boldsymbol{\beta}_{j} \boldsymbol{X}_{i j t}+\eta_{i j t}+\omega_{i j t}-\boldsymbol{\beta}_{j} \boldsymbol{X}_{i j t-2}+\eta_{i j t-2}+\omega_{i j t-2}
$$

Now define

$$
g_{i j t}=\Delta\left(y_{i j t}-\boldsymbol{\beta}_{j} \boldsymbol{X}_{i j t}\right)=\Delta \eta_{i j t}+\epsilon_{i j t}
$$

and

$$
g_{2 i j t}=\Delta_{2}\left(y_{i j t}-\boldsymbol{\beta}_{j} \boldsymbol{X}_{i j t}\right)=\eta_{i j t}+\omega_{i j t}-\eta_{i j t-2}-\omega_{i j t-2}=\eta_{i j t}-\eta_{i j t-2}+\epsilon_{i j t}+\epsilon_{i j t-1} .
$$

To identify the parameters of interest, we compute

$$
E\left(g_{2 i j t} g_{2 i j t}\right)=2 \sigma_{\epsilon_{i j}}^{2}+2 \sigma_{\eta_{i j}}^{2}
$$

and 


$$
E\left(g_{i j t} g_{i j t-1}\right)=-\sigma_{\eta_{i j}}^{2}
$$

To estimate the variances of the two innovations, we proceed as follows. For a

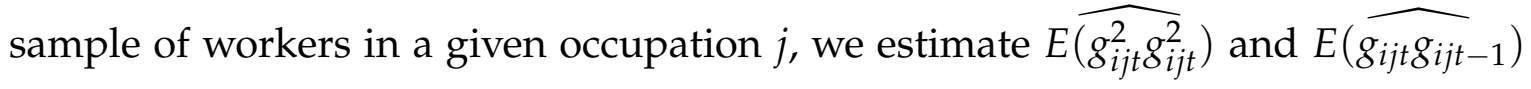
using the sample analogs. Solving the system composed of the previous two equations, we obtain $\widehat{\sigma_{\epsilon_{j}}^{2}}$ and $\widehat{\sigma_{\eta_{j}}^{2}}$.

\subsubsection{Results}

Table 1 shows the estimated variance of the permanent shocks to labor earnings by occupation and country. There are substantial differences in earnings uncertainty across occupations. For instance, U.S. sales workers face higher permanent risk than teachers. Risk also differs across the two countries; generally, the United States is riskier than Germany. However, certain occupations are safer in the United States than in Germany and viceversa. For example, managerial workers face less risk in the United States whereas the opposite is true for manufacturing workers. Although in our quantitative analysis we take these differences as exogenous, they may reflect differences in the labor markets of these two countries. ${ }^{18}$ What is relevant for our analysis is how workers react to uncertain earnings and by how much this reaction is affected by social insurance policies.

\subsection{Income Tax Progressivity}

The United States and Germany differ in the degree of tax progressivity. Holter, Krueger, and Stepanchuk (2015) estimate parametric functions of the income tax schedule for several countries. That estimation takes into account transfers and it fits the actual schedule well except for the lowest income levels. Specifically the tax functions take the following form,

$$
y_{a}=\phi_{0} y_{p}^{1-\phi_{1}}
$$

\footnotetext{
${ }^{18}$ For example, the Kurzarbeit scheme in Germany implemented during the Great Recession shares risk across workers. Employers reduce the average hours worked by all employees instead of laying off some employees. A lower variance of earnings in Germany reflects to some extent such practices.
} 
where $y_{a}$ and $y_{p}$ are after- and pre-tax earnings respectively. We borrow the estimates from Holter, Krueger, and Stepanchuk (2015) for the United States and Germany: $\phi_{0, G E R}=0.779, \phi_{1, G E R}=0.198, \phi_{0, U S A}=0.818$, and $\phi_{1, U S A}=0.111 .^{19}$ Figure 1 show the two functions. Germany's income tax is much more progressive than that of the United States. In our quantitative study that follows we take these tax functions as exogenous.

\subsection{Risk and Occupational Mobility}

With these estimates of earnings risk in hand, we now examine occupational mobility rates. Due to restrictions in the frequency of the U.S. data, we compute 2-year mobility rates for both countries. We define those as the proportion of workers who change occupations between two consecutive periods (being the period, 2 years, and conditional on being present in the sample in both periods). Occupational mobility in the United States is much higher than in Germany. We find that on average $25 \%$ of U.S. workers change occupations, but only $3.7 \%$ of German workers do. ${ }^{20}$

Despite the extra-insurance provided by a more progressive tax system, Germany's mobility rate is lower. However, because the level of earnings uncertainty is so much lower in Germany than in the United States, we are rather interested in the following question: Given a shock to earnings of the same magnitude, is a U.S. worker more or less likely to switch occupations? To find an answer we move beyond raw mobility rates and estimate a logit model that relates occupational mobility to the earnings shocks experienced and to several other controls.

For the estimation of the two statistical models below, we restrict the analysis to pre-1997 data. ${ }^{21}$ We estimate the following panel earnings regression:

$$
y_{i t}=\alpha_{i}+\eta H_{i t}+v_{i t}
$$

\footnotetext{
${ }^{19}$ These parameters are for singles, since our quantitative framework does not model the household explicitly. The parameters are reported in the last column of Table 4 in Holter, Krueger, and Stepanchuk (2015).

${ }^{20}$ Kambourov and Manovskii (2009) report that 1-year mobility rates in the United States in the 1990 s are roughly $21 \%$. Our estimate is slightly higher because we focus on 2-year rates.

${ }^{21}$ The reason is that the PSID became biennial that year.
} 
The notation is similar to that of equation (1): $y_{i t}$ is log earnings per hour of individual $i$ at time $t, \alpha_{i}$ is an individual fixed effect, and the vector $\boldsymbol{H}$ includes several variables that help predict changes in the level of log earnings. Specifically, we include age, sex, ethnicity, education, occupation, industry, and time dummies. The only difference between equations (10) and (1) is that the former includes switchers and non-switchers-hence the lack of an occupational subscript $j$. We estimate this regression for each country to obtain $\hat{v}$. These estimated residuals represent the realized shocks to earnings that individuals experience. Some of the shocks occur while a worker is in an occupation, but some other shocks precede an occupational switch.

We assume that the probability of switching occupations is a function of realized (lagged) earnings shocks (and possibly additional variables):

$$
P_{i, t} \equiv \operatorname{Pr}\left(y_{i, t}=1 \mid \hat{v}_{i, t-1}^{-}\right)=E\left(y_{i, t} \mid \hat{v}_{i, t-1}^{-}\right)=\psi\left(\hat{v}_{i, t-1}^{-} ; \beta\right) .
$$

In this specification, $P_{i}$ is the probability that individual $i$ switches occupations and $\psi$ is the logit function. The variable $p_{i}$ is a binary variable that takes the value 1 if worker $i$ switches the occupation between period $t$ and $t+1$. The variable $\hat{v}^{-}$ represents the negative values of $\hat{v}$; if $\hat{v}$ is positive, $\hat{v}^{-}$is set to $0 .{ }^{22}$

We label the absolute value of the coefficient associated with $\hat{v}^{-}$the propensity to switch. The sign is negative when a negative shock increases the likelihood of an occupational switch. The value of the propensity to switch allows us to compare occupational mobility between the United States and Germany for a shock of equal value. Table 2 reports the result of the estimation for both countries. The value of the coefficient estimated for Germany is -0.043 and for the United States is -0.03 . These numbers imply that the propensity to switch is about the same in Germany as in the United States; actually, it is higher for Germany in this particular sample.

To summarize, vastly higher mobility rates may lead us to conclude that U.S.

\footnotetext{
${ }^{22}$ The reason for not using the raw residuals is the pattern studied by Groes, Kircher, and Manovskii (2015). They find that when sorted by earnings, workers at both ends of the distribution are more likely to switch occupations. The quantitative model we use below ignores occupational switches that result from large positive earnings shocks and relates only to negative ones. For this reason we focus on the negative values of the residual, setting other values to 0 .
} 
workers are more responsive to shocks than German workers. Our estimates show that this conclusion is mistaken; higher mobility rates arise naturally when shocks are more variable. Our estimates imply a large similarity in the reaction of U.S. and German workers to earnings shocks. A question that remains is why-if social insurance is important- is the propensity to switch not higher in Germany than in the United States? To answer it we need to consider other determinants influencing the switching decision. To that end, we use a quantitative model that, calibrated to Germany and the United States, shows that the estimated propensity to switch in Germany would be higher if it were not for higher mobility costs. In other words, Germany's ample social insurance encourages mobility but this is partly offset by higher switching costs.

\section{Quantitative Model}

\subsection{Households}

The economy is populated by a continuum of workers who value the consumption of a final good. Every period they are endowed with a unit of time. They live for $S$ periods, financing consumption using labor earnings. Workers rank levels of consumption $c$ of the final good according to a utility function $u(c)$. This function is concave, and as a result, workers dislike risk. Finally, workers do not value leisure, supplying all of their time in a labor market described in detail below.

\subsection{The Labor Market}

The labor market is divided into sub markets, one for each occupation. There are $J$ occupations available labeled by index $j$ from 1 to $J$. Occupations are mutually exclusive; workers can work in only one occupation during any given period. However, they may switch occupations between periods. During their tenure in occupation $j$, workers receive a wage $w_{j}$ per unit of their human capital. Human capital comes in two varieties. The first variety is an occupation-specific ability. At birth, each worker is characterized by a vector $\left\{\theta_{j}\right\}_{j=1}^{J}$. Prior to entering the labor market, the elements of this vector are unknown. Its values are discovered 
sequentially as workers experiment and sample different occupations. For a given occupation $j$, the value of $\theta_{j}$ is revealed to the worker the first time occupation $j$ is tried. Once discovered, the worker retains that specific $\theta_{j}$, even if he eventually switches to other occupations. In what follows, it is convenient to define the set $J(s)$ as the set of occupations tried by (the beginning of) age $s$, and $\{\tilde{\theta}\}_{j \in J(s)}$ as the set of abilities for those occupations already tried.

The second type of human capital is general and therefore transferable across occupations. The stock of this type of human capital, denoted by $z$, evolves over a worker's career. Despite its generality, the evolution of this type of human capital depends on the worker's current occupation. To be more specific, while working in a given occupation, $z$ changes randomly, and the shocks that affect it are occupation-specific. Shocks to $z$ are an additional source of occupational mobility and are denoted by $\epsilon$. Formally, while an individual works in occupation $j$, his general human capital evolves according to $z^{\prime}=z+\epsilon_{j}$, and $\epsilon_{j} \sim N\left(0, \sigma_{j}^{2}\right)$. We are agnostic about the exact nature of these shocks. They capture, for example, the interaction between a worker's skills and an occupation's response to technological innovation. In other words, occupations react differently to changes in technology, and given such a reaction, a worker's human capital may suffer more or less depending on his portfolio of skills. At any rate, as the evidence in Section 2.2 shows, occupation-specific shocks to earnings are a feature of the data.

\subsection{Technology}

There is a set of $J$ intermediate service producers indexed by $j$. We associate such services with occupations. The quantity of intermediate service $j$ each produces is $X_{j}$ using a linear technology in labor $N_{j}$, that is, $X_{j}=N_{j}$. The producer faces prices for her service $p_{j}$ and wages $w_{j}$. Both intermediate services and labor markets are competitive.

The producer of intermediate service $j$ solves the following maximization problem:

$$
\max _{N_{j}} p_{j} X_{j}-N_{j} w_{j}
$$


subject to $X_{j}=N_{j}$. Intermediate service producers sell to a final goods producer. To produce $Y$ units of the final good, a Cobb-Douglas technology aggregates intermediate services $\left\{X_{1}, \ldots, X_{J}\right\}, 23$

$$
Y=\prod_{j=1}^{J}\left\{X_{j}^{\alpha_{j}}\right\}
$$

The final goods producer faces purchase prices $\left\{p_{j}\right\}_{j=1}^{J}$ for the different occupations. The final good is the numeraire and its price is 1. Formally, its producer solves,

$$
\max _{\left\{X_{1}, \ldots, X_{J}\right\}} \prod_{j=1}^{J}\left\{X_{j}^{\alpha_{j}}\right\}-p_{j} X_{j} .
$$

Note that in equilibrium $X_{j}=N_{j}$ and $p_{j}=w_{j}$, so the solution to this maximization problem implicitly defines labor demand functions $\left\{N_{j}=N_{j}^{d}\left(w_{j}, N_{-j}\right)\right\}_{j=1}^{J}$

\subsection{Worker Optimization}

At the beginning of the period the worker faces an occupational choice decision. The worker knows her current level of general human capital $z$ and the shock in the current occupation $\epsilon_{j}$. She can remain in her current occupation, with total general human capital equal to $z+\epsilon_{j}$ and known ability $\theta_{j}$. Alternatively, she can try another occupation. Some of the alternatives have never been tried before and for those the ability $\theta$ is unknown. Define by $W_{s}\left(\Omega_{s}, z, \epsilon, j\right)$ the maximum value an age-s agent obtains by choosing among $J$ mutually exclusive occupations. This choice depends on the set of occupations the worker has visited before $J(s-1)$, as well as her associated abilities $\left\{\theta_{j}\right\}_{j \in J(s-1)}$. These two elements make up $\Omega_{s}$. The choice also depends on the current stock of general human capital $z$, its current innovation $\epsilon$, and the current occupation $j$.

The following expression formally describes the choice between a known occupation $j$ and a set of alternative occupations $j^{\prime}$.

$$
W_{S}\left(\Omega_{s}, z, \epsilon, j\right)=\max \left\{V_{S}\left(\Omega_{s}, z, \epsilon, j\right),\left\{V_{s}\left(\Omega_{s}, z, j^{\prime}\right)\right\}_{j^{\prime} \neq j}\right\} .
$$

\footnotetext{
${ }^{23}$ We assume no capital in this version but it is an easy-to-add feature.
} 
The value of remaining in the current occupation $j, V_{s}\left(\Omega_{S}, z, \epsilon, j\right)$, is conditional on a particular value of the random variable $\epsilon$ (the shock to general human capital $z$ ). Alternative occupations-those labeled $j^{\prime}$-never depend on $\epsilon_{j^{\prime}}$ and depend on $\theta_{j^{\prime}}$ only if it is already known - that is, if the worker has worked in $j^{\prime}$ at some point in his past.

The value of staying is given by the maximum value attained by working in occupation $j$ :

$$
\begin{gathered}
V_{s}\left(\Omega_{s}, z, \epsilon, j\right)=\left\{u(c)+\beta \int W_{s+1}\left(\Omega_{s+1}, z^{\prime}, \epsilon^{\prime}, j\right) d F_{j}\left(\epsilon^{\prime}\right)\right\}, \text { s.to } \\
c=T\left(w_{j} e^{\theta_{j}} e^{z} e^{\epsilon}\right) \\
z^{\prime}=z+\epsilon \\
\Omega_{s+1}=\Omega_{s}
\end{gathered}
$$

The continuation value is the maximum among $J$ occupations, knowing that productivity in occupation $j$ will experience a shock $\epsilon^{\prime}$. The flow budget constraint (15) equates consumption to total income, which is simply after-tax earnings $T\left(w_{j} e^{\theta_{j}} e^{z} e^{\epsilon}\right)$. Pre tax earnings are equal to the product of a wage rate $w_{j}$ and the amount of efficiency units $e^{z} e^{\theta_{j}} e^{\epsilon}$. A progressive tax function $T(\cdot)$ applied to pre tax earnings gives the after-tax amount available to finance expenditures. Recall that this function is given by $y_{a}=T\left(y_{p}\right)=\phi_{0} y_{p}^{1-\phi_{1}}$, where $y_{p}$ and $y_{a}$ are preand after-tax earnings, respectively. ${ }^{24}$

The (log of) general human capital $z$ evolves according to (16). The current shock $\epsilon$ is added to the stock $z$ to update it to its new value $z^{\prime}$. Finally, remaining in the same occupation adds no new information to $\Omega_{s}$, and as a result $\Omega_{s+1}=\Omega_{s}$.

By switching occupations a worker bets that his performance will improve as a result of the change. If the worker has chosen that occupation for the first time, the outcome is uncertain because both $\epsilon$ and $\theta$ in that prospective occupation are unknown. The worker takes expectations with respect to both distributions to compute the value of the alternative occupation. If at some point the worker has

\footnotetext{
${ }^{24}$ We assume government revenues are wasted.
} 
tried occupation $j^{\prime}$, only the value of $\epsilon$ is uncertain.

Recall that $\Omega$ includes the set $J(s-1)$, the set of inspected occupations. If $j^{\prime}$ is not an element of $J(s-1)$, the value of the alternative occupation is

$$
V_{s}\left(\Omega_{s}, z, j^{\prime}\right)=\int V_{s}\left(\Omega_{s}, \theta, z, \epsilon, j^{\prime}\right) d G_{j^{\prime}}(\theta) d F_{j^{\prime}}(\epsilon) .
$$

Conditional on a particular $\theta$ and $\epsilon$, the value of the alternative occupation is the maximum attained by adding the utility flow from earnings plus the continuation value:

$$
\begin{aligned}
& V_{s}\left(\Omega_{s}, \theta_{j^{\prime}}, z, \epsilon, j^{\prime}\right)=\left\{u(c)+\beta \int W_{s+1}\left(\Omega_{s+1}, z^{\prime}, \epsilon^{\prime}, j^{\prime}\right) d F_{j^{\prime}}\left(\epsilon^{\prime}\right)\right\} \text {, s.to } \\
& c=T\left(w_{j^{\prime}} e^{z} e^{\theta_{j^{\prime}}} e^{\epsilon_{j^{\prime}}} e^{-c(s, \kappa)}\right) \\
& z^{\prime}=z+\epsilon_{j}^{\prime} \\
& \Omega_{s+1}=\left\{\Omega_{s}, j^{\prime}, \theta_{j^{\prime}}\right\} .
\end{aligned}
$$

This value is similar to that of remaining in the same occupation. There are two differences. First, according to (22) the set $\Omega_{s}$ grows, because the worker obtains new information about his ability in the new occupation $j^{\prime}$. The second difference is the term $e^{-c(s, \kappa)}$, affecting the amount of efficiency units and reflecting a (temporary) human capital loss. This cost is borne by all switchers, regardless of whether the new occupation has been tried before. The function $c(s, \kappa)$ reflects mobility costs; it depends on age and on a vector of parameters $\kappa$. This specification permits modeling in a flexible way the mobility costs facing workers as they age.

Evaluating an occupation $j^{\prime}$ that has been visited before is simpler. The only uncertainty facing the worker is with respect to the shock $\epsilon$ in $j^{\prime}$. The alternative value for this case-the analog to equation (18)—can be written as

$$
V_{s}\left(\Omega_{s}, z, j^{\prime}\right)=\int V_{s}\left(\Omega_{s}, z, \epsilon, j^{\prime}\right) d F_{j^{\prime}}(\epsilon) .
$$

Note that the ability parameter $\theta_{j^{\prime}}$ is an element of $\Omega_{s}$, because the worker has previously visited that occupation. The calculation of the value of switching is 
almost identical to (19)-(22). The exception is equation (22), which now becomes (17): The set $\Omega_{s}$ does not change because no new information is revealed about the worker's innate abilities.

The previous description of the occupational decision problem holds for all periods except the first one. In the first period a fraction $f_{j}$ of workers is exogenously assigned to occupation $j$. These workers learn their comparative advantage in that occupation but experience no $\epsilon$ shocks (i.e., their $z$ is 0 ). In the second and subsequent periods they optimally choose their occupation as described above.

\subsection{Equilibrium}

Let us denote the policy function that describes the occupational decision of an individual of age $s$ characterized by a realization $\epsilon$, a set $\Omega_{s}$ and productivity $z$, who is currently in occupation $j^{\prime}$ and who switches to occupation $j$ by $I_{j, s}\left(j^{\prime}, \omega, z, \epsilon\right)$.

For aggregation purposes it is necessary to specify the position of individuals across states. Let $\Psi_{j, s}\left(\Omega_{s}, z, \epsilon\right)$ be the mass of individuals of age $s$ in occupation $j$, with productivity $z$, and shock $\epsilon$ who have been in other occupations in the past with their respective ability, represented by $\Omega_{s}$. The measure $\Psi$ is defined for all the possible values of $\Omega_{s}, z$ and $\epsilon$ that belong to sets that are Borel subsets of $\mathbb{R}$.

The dynamic evolution of the mass of individuals reads as follows. As described above, the mass of newborns in occupation $j$ is exogenously determined and given by $f_{j}$. Thus, for $s=0$,

$$
\Psi_{j, 0}\left(\Omega_{0}, z, \epsilon\right)=\frac{1}{S} f_{j} \quad \forall \quad j \in\{1, \ldots, J\} .
$$

In addition, since individuals live $S$ number of years, we have that for $S+1$,

$$
\Psi_{j, S+1}\left(\Omega_{S}+1, z, \epsilon\right)=0 \quad \forall \quad j \in\{1, \ldots, J\}
$$

For $0<s<S, \Psi$ obeys the following recursion 


$$
\Psi_{j, s+1}\left(\Omega_{s+1}, z, \epsilon\right)=\sum_{j^{\prime}} \Psi_{j, s}\left(\Omega_{s}, z, \epsilon\right) I_{j, s}\left(j^{\prime}, \omega_{s}, \epsilon\right) \quad \forall \quad j^{\prime} \in\{1, \ldots, J\} .^{25}
$$

The aggregate mass of efficiency units in each occupation is thus given by

$$
N_{j}=\frac{1}{S} \sum_{s \in S} \int e^{z} e^{\theta_{j^{\prime}}} e^{\epsilon_{j^{\prime}}} d \Psi_{j, s}\left(\Omega_{s}, z, \epsilon\right)+\frac{1}{S} \sum_{s \in S} \sum_{j \neq j^{\prime}} \int e^{-c(s, \kappa)} d \Psi_{j^{\prime}, S-1}\left(\Omega_{s-1}, z, \epsilon\right)
$$

We can now define a stationary competitive equilibrium that consists of (i) a set of occupation-level wages $\left\{w_{j}\right\}_{j=1}^{J}$; (ii) occupation populations (or masses) $\left\{\psi_{j}\right\}_{j=1^{\prime}}^{J}$ (iii) a set of intermediate goods prices $\left\{p_{j}\right\}_{j=1}^{J} ;$ (iv) occupation-level efficiencyweighted employment levels $\left\{N_{j}\right\}_{j=1}^{J}$; and (v) occupation-specific decision rules $\left\{I_{j, s}\right\}_{j=1}^{J}$ and associated value functions $\left\{V_{s}\right\}_{s=1}^{S}$ that satisfy the following conditions:

1. The labor inputs $N_{j}$ are the solution to the intermediate producer optimization problem.

2. The intermediate goods quantities $X_{j}$ solve the final goods producer's problem.

3. Prices $p_{j}$ equate supply and demand of intermediate goods.

4. The wage in occupation $j$ is the marginal product of a unit of efficiency in that occupation:

$$
w_{j}=\alpha_{j} N_{j}^{\alpha_{j}-1} \prod_{j^{\prime} \neq j}\left\{{N_{j}^{\prime}}^{\prime \prime}\right\}
$$

5. Labor markets clear at the occupational level.

6. In a given occupation $j, \Psi_{j}$ is the stationary distribution.

By Walras's law, the market for the final good also clears.

\footnotetext{
${ }^{25}$ Note that $j^{\prime}$ can take the value $j$ since there is a mass of individuals who were in $j$ and stay in $j$.
} 


\section{Quantitative Analysis}

\subsection{Parameter Values}

We separately calibrate our model economy to German and U.S. data; the calibration strategy is identical for the two economies. There is a set of parameters common to the two countries and a set of parameters that differ. The common set of parameters includes the period frequency, the number of occupations $J$, the discount factor $\beta$, the coefficient of relative risk aversion $\gamma^{26}$ and the life span $S$.

We restrict the analysis to an economy with three occupations grouped according the level of risk: safe $(S)$, medium $(M)$, and risky $R \cdot{ }^{27}$ The model period is set equal to 1 year and a worker's lifetime $S$ is 35 years. We set the relative riskaversion coefficient $\gamma$ equal to 3 , and the discount factor $\beta$ equal to 0.96 . The value for $\gamma$ is well within the range of typically used figures. The value for $\beta$ is consistent with a real interest rate of $4 \%$ in an infinite-horizon economy with complete markets when the period is one year.

The values for the remaining parameters are country-specific. We choose values so that our model economy replicates features of the actual economy. We assume that the distribution of shocks to human capital $z$ and the distribution of abilities $\theta$ are normal:

$$
\begin{aligned}
& \epsilon_{j} \sim N\left(-0.5 \sigma_{\epsilon, j}^{2}, \sigma_{\epsilon, j}^{2}\right), \\
& \theta_{j} \sim N\left(-0.5 \sigma_{\theta, j}^{2}, \sigma_{\theta, j}^{2}\right),
\end{aligned}
$$

for $j$ in $\{S, M, R\}$. We also assume a quadratic mobility cost function $c(s, \kappa)$ :

$$
c(s, \kappa)=\kappa_{0}+\kappa_{1} s+\kappa_{2} s^{2}
$$

\footnotetext{
${ }^{26}$ The utility function $u(c)$ is of the constant relative risk-aversion class:

$$
u(c)=\frac{c^{1-\gamma}}{1-\gamma} .
$$

${ }^{27}$ We rank the 12 occupations by the variance of the permanent shock. The $S$ group of occupations is defined as those with the lowest level of risk and include around $25 \%$ of workers. Analogously, the $R$ group is the set of occupations with the highest permanent risk that include around $25 \%$ of workers.
} 
The set of parameters that are country-specific is

$$
\Lambda=\left\{\kappa_{0}, \kappa_{1}, \kappa_{2},\left\{\sigma_{\epsilon, j}^{2}, f_{j}, \sigma_{\theta, j}^{2}, \alpha_{j}\right\}_{j \in S, M, R}\right\}
$$

where we have included the new parameters $f_{S}, f_{M}$, and $f_{R}$ that refer to the initial fractions of workers in each of the three occupations. It is important to note that we do not take the variances as estimated in the empirical part; we calibrate them. By that we mean that the set of $\left\{\sigma_{\epsilon, j}^{2}\right\}_{j=1}^{J}$ includes parameters to be estimated jointly so that the model delivers a set of moments described below. Since the reduced-form econometric procedure described in Section 2.2 does not consider occupational change, its estimated variances underestimate the true uncertainty workers experience. The reason is simply selection: large negative shocks to labor earnings are the reason workers switch occupations.

The value of some of these parameters can be calculated directly from the data. First, the parameters $f_{S}, f_{M}$, and $f_{R}$ correspond to the fractions of the youngest group of workers in each of the three occupations. Of the 26-years-old, $32.5 \%$ work in the safe occupation in the United States and 32.95\% in Germany. For the medium and the risky occupations, there is more disparity across the two economies. For the medium-risk occupation, the fraction is close to a half for Germany (47.62\%) while it is less than $40 \%$ for the United States $(38.2 \%)$. The labor share parameters $\alpha_{j}$ for $j \in\{S, M, R\}$ can be computed outside the model as well. Because the final good employs occupation services, and the amount of those services equals the total amount of efficient units of labor provided by workers in that occupation, $\alpha_{j}$ represents the wage bill in occupation $j$ as a share of the total wage bill. Therefore, one can calculate $\alpha_{j}$ as total earnings in occupation $j$ as a fraction of total earnings across all occupations. ${ }^{28}$

We choose the values for remaining country-specific parameters so that the model matches a set of moments from the data. Table 3 displays their values for the United States (first column) and for Germany (second column). We first consider the mobility of workers across occupations. In particular, one of the

\footnotetext{
${ }^{28}$ Because production of the final good does not require capital, total output is equal to the total wage bill.
} 
moments to match is the average 2-year mobility rates for the young, middle-aged, and old workers. ${ }^{29}$ As before, we compute 2-year mobility rates for each age group (for a total of 33 age groups). We then take the average of those for the 28to-38-year-olds (young), the 39-to-49-year-olds (middle-aged), and those 50 years or older (old). Section 2.4 reports that mobility is much higher in the United States than in Germany and the difference is largest for young workers. In the United States, about $22.36 \%$ of young workers switch occupations in 2 years. This fraction drops to only $19.74 \%$ for the middle-aged and to $17.97 \%$ for the older group. The corresponding figures for Germany are $4.1 \%, 2.1 \%$, and $0.9 \%$.

We also target (i) the variance of the log earnings for the 26-year-olds (by occupation) and (ii) the standard deviation of the permanent shocks to labor earnings, also by occupation. To be clear, the variances of permanent shocks to earnings calculated in Section 2.2 are moments for the model to match. Recall that these are estimated for a panel of workers using spells of work in the same occupation. The model counterpart to those moments is computed in an identical way using the methodology described in Section 2.2. Because we aggregate to 3 occupations, we compute the averages of the standard deviations calculated for our original group of 12 occupations (properly weighted).

The middle three rows of Table 3 show the variances of log earnings for the youngest age group in our sample for both Germany and the United States. The variances in Germany are lower than those in the United States by a factor of about 4 for the safest occupation (0.191 vs. 0.052) and a factor of roughly 2 for the riskiest (0.165 vs. 0.089$)$. The variability of permanent shocks to earnings is also higher for U.S. workers-so much so that the variance of the riskiest occupation in Germany is equal to that of the safest occupation in the United States (0.101).

Table 4 displays the values of the parameters for the U.S. and German economies. Mobility costs are higher in Germany than in the United States. Potentially, they could be key in explaining the differences in occupational mobility between these two countries. However, below we show that these higher mobility costs matter

\footnotetext{
${ }^{29}$ Mobility rates now are defined as switches among our 3 occupations grouped by risk, not the original 12 occupations considered earlier.
} 
little in explaining the differences in mobility rates. The main factor is actually the cross-country differences in the variability of shocks to $\theta$ and to $\epsilon$. As expected, the calibrated variances of the permanent shocks to earnings (the "true" variances of permanent shocks facing workers) are larger than those estimated from spells in the same occupation in Section 2.2 (the targeted moments).

Table 5 shows the targeted moments and the model-simulated moments for the two economies using the parameter values in Table 4 . The two sets of numbers are virtually indistinguishable. The only exception is perhaps mobility for the young in Germany, for which the model delivers too high a rate.

Solving the model for the set of parameter values just described delivers an equilibrium distribution of earnings within and across occupations. In equilibrium, individuals' earnings depend on the occupation wage, and on the realizations of the occupation-specific abilities and the shocks to general human capital. In equilibrium, average earnings within an occupation depend on the wage rate for that occupation and the efficiency units of the workers who selected into that occupation. However, insofar as the variances of the shocks affect the sorting of risk-averse workers, they influence the equilibrium distribution of earnings across occupations as well.

In addition to the baseline model economy, we consider three counterfactual economies that are useful for exploring the mechanisms present in the model. At the same time, they are also useful for assessing how changes in taxation affect prices and allocations. In the first counterfactual we assign the tax function of Germany to the U.S. economy (and vice versa). In the second counterfactual, we force workers to face the other country's risk to general human capital. Finally, in the third counterfactual we set $\theta$ to 0 , so that the innate ability in each occupation is 1 for each worker. In Tables 6, 7, and 8 we present the results for the eight economies we consider (four economies for each country). The next sections summarize these results. 


\subsection{The Effect of Social Insurance: Tax Reforms}

We first analyze the U.S. economy with the more progressive German income tax. All other parameters remain the same. ${ }^{30}$ The third column of Table 6 presents the results. Giving U.S. workers more social insurance raises occupational mobility. Workers now switch on average 4.3 times over their lifetimes $(38.7 \%$ higher than in the baseline). The average mobility rate over the life cycle is now $20 \%$ (1.5 percentage points higher than in the baseline). More insurance encourages experimentation. The discovery of one's innate abilities happens sooner. Also, risky occupations become more attractive, but because they are risky, large number of workers leave those occupations as well.

The higher mobility rate leads to a better assignment of workers to occupations. That better assignment leads to sizable increases in output: It rises from 0.728 to 0.755 (an increase of 3.65\%). Inequality, measured by the variance of log earnings, rises from 0.7 to 0.722 (third line). Note, however, that earnings here refer to pre tax earnings. More social insurance leads to a lower volatility of after-tax earnings. To summarize, more social insurance, everything else constant, raises aggregate output and increases mobility.

The fourth column of Table 7 shows the shares of workers and mean earnings in each occupation. Both in the baseline economy and in the counterfactual the medium-risk occupation is the largest. The smallest is also the riskiest, which also happens to have the highest level of mean earnings. In both cases there is a positive correlation between the level of risk and mean earnings, confirming the results of Cubas and Silos (2017). The higher the risk workers face, the higher the mean earnings. This result is a consequence of the selection of the highestproductivity workers. Compared with the baseline economy, the economy with German taxes exhibits a larger risky occupation, a similar-in-size safe occupation, and a smaller medium-risk occupation. With more insurance, the risky occupation becomes more attractive, and so in equilibrium more workers select into it. As a

\footnotetext{
${ }^{30}$ This is a revenue-neutral experiment. We adjust the parameter $\phi_{0}$ in the tax function, so that the revenue-to-GDP ratio are the same in the U.S. baseline economy and in the U.S. economy with German progressivity.
} 
result, the marginal worker in the risky occupation is of lower ability, contributing to the lower mean earnings.

To investigate the welfare effects of such a policy change, we compute the consumption equivalent variation $(\mathrm{CEV})$. This measure is the uniform percentage change in consumption, at each date and in each event, needed to make a household indifferent between being born into the baseline economy (the U.S. tax system) and being born into the counterfactual economy (the United States with the German tax system). A positive CEV reflects a welfare increase caused by the policy change. Table 8 shows the results. The second column shows that when U.S. workers enjoy Germany's insurance their welfare rises by $2.55 \%$. There are two reasons for this increase. First, it is a result of the standard consumption-smoothing because of the extra insurance. Second, the higher output, a consequence of the better assignment of workers to occupations.

The seventh column of Table 6 shows the results of the alternative experiment: assigning to Germany the less progressive tax system of the United States. Contrary to the previous case and, as expected, occupational mobility declines. This is clear by observing the seventh column of Table 6, which shows the decrease of both the average times workers change occupations (from 0.45 in the baseline to 0.35 ) and the average mobility rate (from $2.5 \%$ to $2 \%$ ). Because U.S. labor taxation discourages risk-taking, workers experiment less. The lower degree of experimentation leads to lower-quality matches. Aggregate output suffers as a result, and relative to the baseline German economy, this counterfactual economy yields $2.6 \%$ fewer goods. Pre tax earnings inequality, measured by the variance of log earnings, falls as well. However, because U.S. taxes are less progressive, after-tax earnings inequality rises. The fifth column of Table 7 shows that there is a substantial increase in the proportion of workers in the risky occupation. Compared with the baseline economy, this economy is much less uncertain. Recall that the riskiest occupation in Germany is as risky as the safest occupation in the United States As a result, the proportion of workers in the safest and medium-risk occupations decreases. Consequently, mean earnings decrease in all occupations but much more in the risky one due to the inclusion of low-productivity workers. 
Regarding the share-measured by the fraction of workers-in each occupation, the results of this counterfactual exercise are qualitatively similar. With less insurance, the fraction of German workers in the risky occupation is almost the same but there are fewer of them in the medium-risk occupation and more in the safe one. Again, as for the United States, there is also compensation for risk in Germany. We also compute CEV for this case and find there are substantial welfare losses, especifically on the order of $4.5 \%$ compared with the baseline German economy. As shown below, the combination of high earnings (i.e., consumption) volatility and lower output is responsible for large welfare losses from adopting this policy.

We estimate the logit regressions presented in the empirical part but use modelgenerated data. Specifically, we regress the occupational mobility and the realization of the negative shocks of the calibrated stochastic process. Table 9 shows the effect of insurance on occupational mobility. For the United States (columns 2 and 3), as more insurance is provided to workers, the more workers change occupations and thus the coefficient is negative and larger (in absolute value) than the baseline case. The same effect is observed for Germany when we assign their workers the lower level of U.S. insurance; the coefficient is still negative but smaller in absolute value.

\subsection{The Effect of Earning Shocks: United States versus Germany}

Our second counterfactual is to assign each of the baseline economies the earnings shocks of the other. In this way, we explore the implications of changing the magnitude of the permanent shocks to the general human capital (exogenous in our model) on the same set of macroeconomic aggregates.

We start by analyzing the U.S. economy but now with the shocks of the magnitude estimated for Germany. As shown in the fourth column of Table 6, as expected, when U.S. workers face much lower permanent shocks to earnings, mobility rates drop substantially: The average mobility rate is almost 14 percentage points lower than in the baseline economy (from $18.5 \%$ to a value of $4.9 \%$ ). The average occupational changes fall from 4.3 to 0.97 . This drop implies that Germany's 
lower shocks volatility is responsible for its low mobility rates. Higher mobility costs play a minor role. Because the high-productivity workers are much less productive (the right tail is much shorter now), aggregate output falls by close to $40 \%$. Earnings inequality falls almost in the same proportion as well because there is less experimentation owing to the fact workers have fewer risk taking opportunities and, as a result, the equilibrium earnings distribution shrinks.

Although output significantly drops, workers now live in an economy with permanent shocks that are substantially lower in magnitude (the variance of shocks are on average one quarter of those estimated for the baseline economy); thus, this effect dominates and as a result renders a welfare gain of $3.73 \%$ (see the third column in Table 8).

In the same way, we assign German workers the permanent shocks of the U.S. economy. Everything else equal, German workers will now live in a much riskier economy, although this economy will offer them better opportunities. As a result, occupational mobility substantially increases as shown in the fourth column of Table 6. The average occupational change during a worker's lifetime increases from 0.35 to 2.16 and the average mobility rate increases almost 10 percentage points (from $2 \%$ to $11.8 \%$ ). As noted earlier, the magnitude of the permanent shocks explains the bulk of the cross-country differences in the observed occupational mobility. The large increase in mobility results in a better sorting of workers and thus a substantially higher level of output, which increases by $23 \%$. Because of the better sorting inequality increases.

As in the case of the tax reforms, we run the logit regressions using the output of the model in these counterfactual exercises. Table 9 shows the effect of the shocks on occupational mobility. For the United States (columns 2 and 4), as workers face shocks lower in magnitude compared with the baseline, the propensity to change occupations decreases. On the contrary, when German workers face the larger U.S. shocks, the propensity to switch increases.

There is no contradiction in finding that a lower variance of shocks decreases mobility, but a lower variance of earnings - because of more progressive taxes increases mobility. With more progressive taxes, the cutoff value of productivity 
that induces a worker to stay in an occupation, rises. Because the distribution of shocks remains the same, there is now a higher probability of a realization below this cutoff value, encouraging the worker to switch. When the variance of earnings shocks decreases, the uncertain occupation becomes more attractive. This increases mobility, everything else constant. However, low realizations of shocks are now less likely - because of the lower variance - which reduces mobility. The second effect dominates.

\subsection{The Case of Homogeneous Workers}

The last counterfactual economy we examine is one in which there is no heterogeneity in ex ante abilities to work in different occupations or comparative advantages. Specifically, in this counterfactual economy, abilities for working in different occupations are the same and normalized to unity. In this way, we eliminate the mobility that occurs for the process of discovery of workers comparative advantage.

In both countries, occupational mobility increases (see columns 5 and 9 in Table 6). Without occupation-specific abilities, workers have worse occupation matches and thus they are less attached to them. As a result, for the same shocks they move more often than in the baseline case. The changes in the shares of workers in each occupation are small compared with the previous counterfactuals, and mean earnings in each of them change in the same direction as previously observed.

As already mentioned, the fact that $\theta$ is set to 1 , produces worse matches of workers into occupations compared with the baseline case in which workers have occupation-specific abilities. This worse sorting lowers productivity and, as a result, output. Output is $13 \%$ lower for the United States and $8.5 \%$ lower for Germany. Although occupational mobility is higher, the fact that workers are much more similar compared to the baseline case (ex ante homogeneous) implies that pre tax earnings volatility also decreases in both countries. For the United States the variance of $\log$ earnings decreases from 0.7 in the baseline to 0.559 when $\theta$ is 1 . In Germany the variance of log earnings drops from 0.179 to 0.127 . Interestingly, these experiments allow us to explore the sources of earnings inequality. For the 
United States, the magnitude of the drop in the variance of log earnings in the counterfactual exercise shows that about $20 \%$ of the inequality is due to shocks to $\theta$, while the remainder is due to $\epsilon$-shocks. In Germany, $30 \%$ of the inequality is due to shocks to $\theta$.

\section{Concluding Remarks}

This paper uncovers a new mechanism through which social insurance policies improve the matching of workers to occupations. It does so by proposing a dynamic framework in which insurance mitigates the natural uncertainty of career changes. At the early stages of a worker's career, that uncertainty is mainly about occupation-specific innate abilities. Later in the life cycle, earnings risk in prospective occupations becomes more important. Insurance through redistributive taxation induces workers to bet on career changes, helping them to find their best occupational fit. To quantify the importance of this channel, we take a close look at earnings and occupation dynamics of two economies: Germany and the United States.

We document new facts on earnings risk and its relationship with occupational mobility for Germany and the United States. We find that workers experience substantial earnings uncertainty and that earning shocks are occupation-specific. In addition, cross-country differences in earnings volatility explain the bulk of differences in occupational mobility across countries. Equipped with a quantitative model that describes those data well, we find that better insurance leads to substantial increases in output and welfare, as well as changes in pre tax earnings inequality. Our findings appear to support proposals such as Denmark's Flexicurity policies. Those policies stress the importance of maintaining a fluid and flexible labor market, while insulating workers from adverse earnings shocks. This paper shows that the second aspect of the policy partly determines the first: insurance begets mobility. The model shown here can be the starting point for the evaluation of specific policies in which risk, insurance, and career mobility are fundamental elements. 
To focus on our proposed main mechanism, we abstract from many aspects of the labor market. The omissions may also account in part for individuals' occupational choices. For instance, we take earnings volatility as exogenous. Nonetheless, that volatility is key in explaining cross-country differences in mobility. We hope that these and other findings encourage future research on what causes the observed risk across countries and across occupations to vary so widely. For instance, exploring the role of labor market institutions and technological change in explaining cross-country differences in the variance of shocks seems a promising avenue.

We believe our paper offers a new perspective for understanding labor markets, as well as providing new insights on the welfare effects of missing insurance markets. For instance, our results on inequality shed light on the effect of policies targeted to modify initial conditions and those directed at shocks over an individual's working lifetime.

Finally, other types of extensions can also deliver important results. For example, our work has focused on one policy-income taxation-but other types of policies could have similar effects: the provision of health insurance or transfers targeted at children, among others. In addition, the model could be enriched by incorporating self-insurance with a more or less rich asset structure. That extension can yield intriguing insights about the interaction of private and social insurance in determining workers' career choices. 


\section{References}

Acemoglu, D., and R. Shimer (1999): “Efficient Unemployment Insurance," Journal of Political Economy, 107(5), 893-928.

— (2000): "Productivity Gains from Unemployment Insurance," European Economic Review, 44(7), 1195-1224.

Ales, L., M. Kurnaz, and C. Sleet (2015): “Technical Change, Wage Inequality, and Taxes," American Economic Review, 105(10), 3061-3101.

Benabou, R. (2002): “Tax and Education Policy in a Heterogeneous-Agent Economy: What Levels of Redistribution Maximize Growth and Efficiency?," Econometrica, 70(2), 481-517.

Berliant, M., and M. Gouveia (1993): "Equal sacrifice and incentive compatible income taxation," Journal of Public Economics, 51(2), 219-240.

Carroll, C. D., and A. A. Samwick (1997): "The Nature of Precautionary Wealth," Journal of Monetary Economics, 40(1), 41-71.

Conesa, J. C., S. Kitao, and D. Krueger (2009): “Taxing Capital? Not a Bad Idea after All!," American Economic Review, 99(1), 25-48.

Conesa, J. C., and D. Krueger (2006): "On the optimal progressivity of the income tax code," Journal of Monetary Economics, 53(7), 1425-1450.

Cubas, G., and P. Silos (2017): "Career Choice and the Risk Premium in the Labor Market," Review of Economic Dynamics, 26, 1-18.

Dillon, E. W. (2017): "Risk and Return Tradeoffs in Lifetime Earnings," Discussion paper, Arizona State University, Department of Economics.

Eaton, J., and H. S. Rosen (1980a): “Labor Supply, Uncertainty, and Efficient Taxation," Journal of Public Economics, 14(3), 365-374.

(1980b): “Optimal Redistributive Taxation and Uncertainty," Quarterly Journal of Economics, 95(2), 357-364. 
Frick, J. R., S. P. Jenkings, D. R. Lillard, O. Lipps, and M. Wooden (2007): “The Cross-National Equivalent File (CNEF) and Its Member Country Household Panel Studies," EconStor Open Access Articles, pp. 627-654.

Golosov, M., N. Kocherlakota, and A. Tsyvinski (2003): “Optimal Indirect and Capital Taxation," Review of Economic Studies, 70(3), 569-587.

Groes, F., P. Kircher, and I. Manovskii (2015): “The U-Shapes of Occupational Mobility," Review of Economic Studies, 82(2), 659-692.

Guner, N., R. Kaygusuz, and G. Ventura (2014): “Income Taxation of U.S. Households: Facts and Parametric Estimates," Review of Economic Dynamics, 17(4), 559581.

Hawkins, W. B., and J. Mustre del Rio (2012): “Financial frictions and occupational mobility," Discussion paper.

Heathcote, J., K. Storesletten, and G. L. Violante (2014): “Optimal Tax Progressivity: An Analytical Framework," Staff Report 496, Federal Reserve Bank of Minneapolis.

Holter, H. A., D. Krueger, and S. Stepanchuk (2015): “How Does Tax Progressivity and Household Heterogeneity Affect Laffer Curves?," PIER Working Paper Archive 14-039, Penn Institute for Economic Research, Department of Economics, University of Pennsylvania.

Huggett, M., G. Ventura, and A. Yaron (2011): "Sources of Lifetime Inequality," American Economic Review, 101(7), 2923-54.

Jovanovic, B. (1979): “Job Matching and the Theory of Turnover," Journal of Political Economy, 87(5), 972-990.

Kambourov, G., and I. Manovskii (2008): "Rising Occupational and Industry Mobility in the United States: 1968-97,"' International Economic Review, 49(1), 41-79. (2009): "Occupational Mobility and Wage Inequality," Review of Economic Studies, 76(2), 731-759. 
Keane, M. P., and K. I. Wolpin (1997): “The Career Decisions of Young Men," Journal of Political Economy, 105(3), 473-522.

Lee, S. Y., and A. Seshadri (2016): “On the Intergenerational Transmission of Economic Status," Discussion paper, University of Wisconsin-Madison.

- (2017): "Economic Policy and Equality of Opportunity," Discussion paper.

Low, H., C. Meghir, and L. Pistaferri (2010): “Wage Risk and Employment Risk over the Life Cycle," American Economic Review, 100(4), 1432-67.

Miller, R. A. (1984): “Job Matching and Occupational Choice," Journal of Political Economy, 92(6), 1086-1120.

Mirrlees, J. A. (1974): Notes on welfare economics, information and uncertainty. Balch, M., McFadden, D., Wu, S. (Eds.), Essays on Economic Behavior under Uncertainty. North-Holland, Amsterdam: Oxford University Press.

Neumuller, S. (2015): “Inter-industry wage differentials revisited: Wage volatility and the option value of mobility," Journal of Monetary Economics, 76(C), 38-54.

Papageorgiou, T. (2014): “Learning Your Comparative Advantages," Review of Economic Studies, 81(3), 1263-1295.

Rothschild, C., and F. Scheuer (2013): “Redistributive Taxation in the Roy Model," Quarterly Journal of Economics, 128(2), 623-668.

Roy, A. D. (1951): "Some Thoughts on the Distribution of Earnings," Oxford Economic Papers, 3(2), 135-146.

Schupp, J., M. Kroh, J. Goebel, S. Bartsch, M. Giesselmann, M. Grabka, P. Krause, E. Liebau, D. Richter, C. Schmitt, D. Schnitzlein, F. Peter, and I. Tucci (2013): "German Socio-Economic Panel (SOEP), data of the years 1984-2012, version 29, SOEP, 2013," Discussion paper.

Seshadri, A., and K. Yuki (2004): "Equity and efficiency effects of redistributive policies," Journal of Monetary Economics, 51(7), 1415-1447. 
Silos, P., and E. Smith (2015): "Human Capital Portfolios," Review of Economic Dynamics, 18(3), 635-652.

Topel, R. H., and M. P. Ward (1992): “Job Mobility and the Careers of Young Men," The Quarterly Journal of Economics, 107(2), 439-479.

Varian, H. R. (1980): “Redistributive taxation as social insurance," Journal of Public Economics, 14(1), 49-68.

Whittle, P. (1982): Optimization Over Time, Dynamic Programming and Stochastic Control, Wiley series in probability and mathematical statistics . Applied probability and statistics. John Wiley \& Sons. 


\section{Tables}

Table 1: Standard Deviation Permanent Shock

United States

Germany

\begin{tabular}{|c|c|c|c|c|c|c|}
\hline Occupation & $\sigma_{\epsilon}$ & Ranking & No. Workers & $\sigma_{\epsilon}$ & Ranking & No. Workers \\
\hline 1 Professionals and technicians & 0.091 & 4 & 436 & 0.096 & 5 & 1326 \\
\hline 2 Athletes, artists, religion & 0.198 & 11 & 313 & 0.128 & 11 & 693 \\
\hline 3 Managerial Workers & 0.128 & 8 & 674 & 0.149 & 12 & 681 \\
\hline 4 Clerical workers & 0.113 & 6 & 448 & 0.058 & 1 & 1502 \\
\hline 5 Administrative workers & 0.064 & 1 & 281 & 0.114 & 9 & 899 \\
\hline 6 Sales workers & 0.206 & 12 & 335 & 0.102 & 6 & 812 \\
\hline 7 Service workers & 0.089 & 3 & 319 & 0.073 & 3 & 1641 \\
\hline 8 Teachers & 0.124 & 7 & 404 & 0.113 & 8 & 825 \\
\hline 9 Medical workers & 0.186 & 10 & 451 & 0.114 & 10 & 177 \\
\hline 10 Manufacturing workers & 0.088 & 2 & 179 & 0.059 & 2 & 480 \\
\hline 11 Production workers. & 0.130 & 9 & 516 & 0.106 & 7 & 1777 \\
\hline 12 Constructors, painters, transportation & 0.104 & 5 & 634 & 0.075 & 4 & 1447 \\
\hline Weighted Average & 0.130 & & & 0.093 & & \\
\hline
\end{tabular}

Table 2: Logit Regression: United States vs. Germany

\begin{tabular}{ccc}
\hline & United States & Germany \\
$\hat{v}^{-}$ & -0.030 & -0.043 \\
& $(0.010)$ & $(0.005)$ \\
\hline
\end{tabular}

Note: The table displays the results of running a logit regression of the occupationswitching decision on the negative of the earnings residuals $\left(u^{-1}=\min \{u, 0\}\right)$ (second and third columns). The second column shows the result for the PSID and the third column shows the result for the SOEP. 


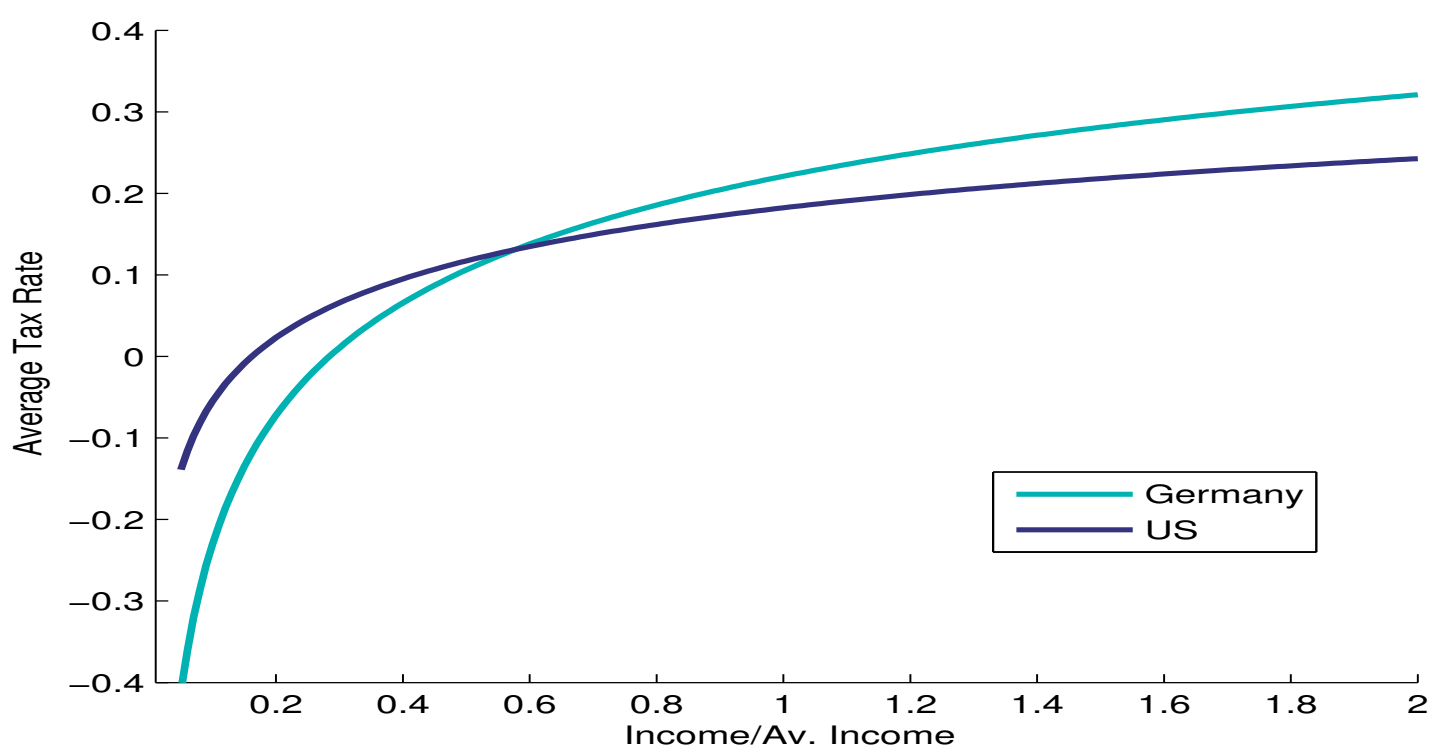

there is

Figure 1: The figure plots the tax functions for Germany and United States estimated in Holter, Krueger, and Stepanchuk (2015)

Table 3: Targeted Moments: United States and Germany

\begin{tabular}{lcc}
\hline & USA & Germany \\
\hline Mob. rate young & 0.224 & 0.041 \\
Mob. rate mid-age & 0.197 & 0.021 \\
Mob. rate old & 0.180 & 0.010 \\
Var. log earnings S & 0.191 & 0.052 \\
Var log earnings M & 0.159 & 0.063 \\
Var. log earnings R & 0.165 & 0.089 \\
SD risk S & 0.101 & 0.063 \\
SD risk M & 0.146 & 0.075 \\
SD risk R & 0.217 & 0.101
\end{tabular}

Note: The table displays the moments and the values targeted in the estimation of the model for the US and Germany. Mob, mobility; M, medium; R, risky; S, safe; $\mathrm{SD}$, standard deviation; Var., variance. 
Table 4: Estimated Parameters: United States and Germany

\begin{tabular}{lcc}
\hline & USA & Germany \\
\hline$\kappa_{0}$ & 1.174 & 1.625 \\
$\kappa_{1}\left(10^{-3}\right)$ & 1.273 & 0.240 \\
$\kappa_{2}\left(10^{-3}\right)$ & -0.942 & -0.808 \\
$\sigma_{\epsilon, S}$ & 0.109 & 0.063 \\
$\sigma_{\epsilon, M}$ & 0.158 & 0.076 \\
$\sigma_{\epsilon, R}$ & 0.271 & 0.101 \\
$\sigma_{\theta, S}^{2}$ & 0.191 & 0.052 \\
$\sigma_{\theta, M}^{2}$ & 0.159 & 0.063 \\
$\sigma_{\theta, R}^{2}$ & 0.165 & 0.089 \\
\hline
\end{tabular}

Note: The table displays the value of the estimated parameters of the model for United States and Germany.

Table 5: Model Fit (Data vs. Model): United States and Germany

\begin{tabular}{lccccc}
\hline & \multicolumn{2}{c}{ United States } & & \multicolumn{2}{c}{ Germany } \\
\cline { 2 - 3 } \cline { 5 - 6 } \cline { 5 - 6 } & Data & Model & & Data & Model \\
\hline Mob. rate young & 0.224 & 0.221 & & 0.041 & 0.046 \\
Mob. rate mid-age & 0.197 & 0.169 & & 0.021 & 0.019 \\
Mob. rate old & 0.180 & 0.168 & & 0.010 & 0.009 \\
Var. log earnings S & 0.191 & 0.190 & & 0.052 & 0.052 \\
Var log earnings M & 0.159 & 0.159 & & 0.063 & 0.063 \\
Var. log earnings R & 0.165 & 0.164 & 0.089 & 0.089 \\
SD risk S & 0.101 & 0.102 & & 0.063 & 0.062 \\
SD risk M & 0.146 & 0.143 & & 0.075 & 0.075 \\
SD risk R & 0.217 & 0.212 & & 0.101 & 0.101
\end{tabular}

Note: The table displays the fit of the model by presenting the values of the targeted moments in the data and their model counterparts. Mob, mobility; M, medium; R, risky; S, safe; SD, standard deviation; Var., variance. 
Table 6: Model Summary: Baseline vs. Counterfactuals

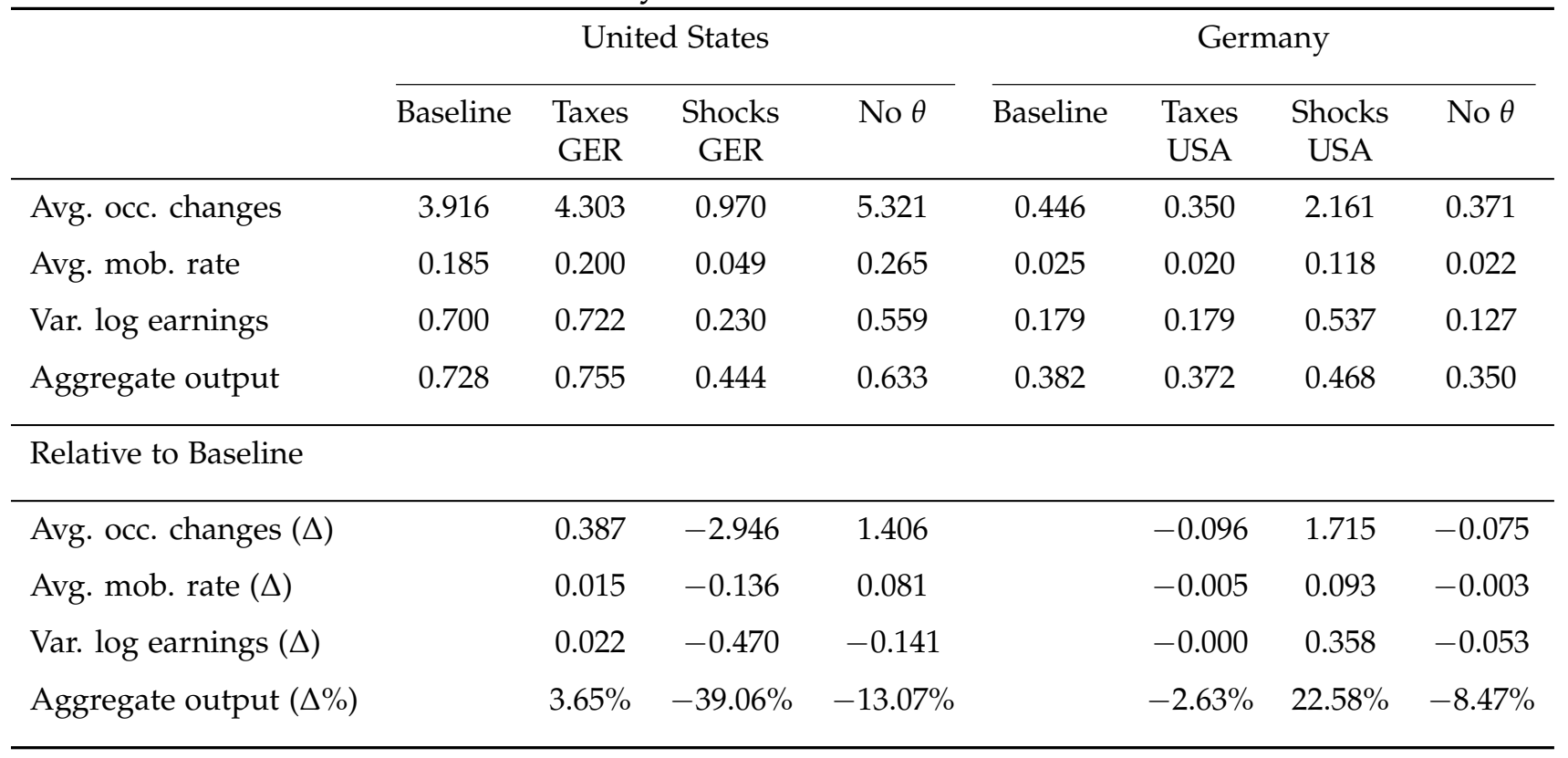

Note: The table present the results of the quantitative model. It shows the value of the average number of occupational changes, the mobility rate, the variances of log earnings and aggregate output for the United States (columns 2 to 5 ) and Germany (columns 6 to 9). The values of columns 2 and 5 refer to the baseline case. Columns 3 and 7 refer to the counterfactual exercise in which each country has the tax policy of the other: Taxes GER is the case of the United States with the tax code of Germany, and Taxes USA is the case of Germany with the tax code of the United States. Columns 4 and 8 refer to the counterfactual exercise in which each country has the earnings shocks of the other-specifically, the standard deviation of the permanent shocks. Shocks GER is the case of the United States with the shocks of Germany and Shocks USA is the case of Germany with the shocks of the United States. Columns 5 and 9, labeled as "No $\theta$ ", refer to the counterfactual exercise in which workers are ex ante homogeneous. The first panel presents the levels and the second the change with respect to the baseline case. Avg., average; mob., mobility; occ., occupational; Var., variance.

Table 7: Model Summary: Baseline vs. Counterfactuals

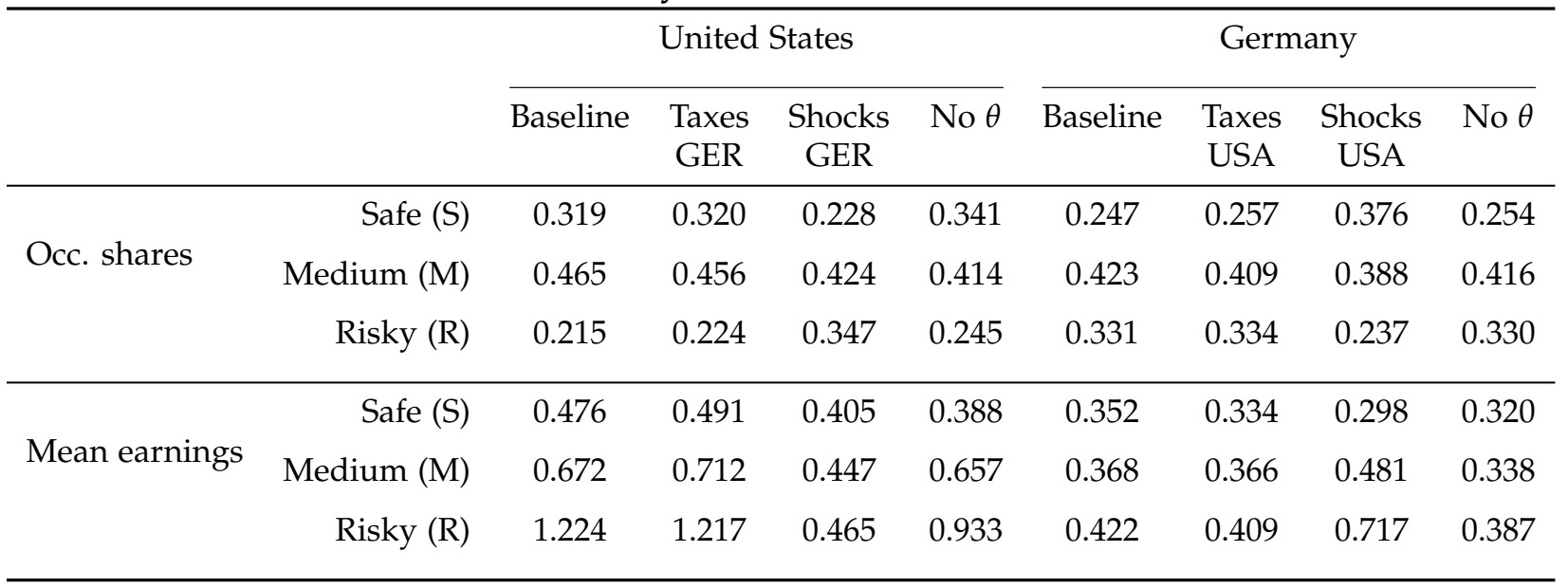

Note: The table presents the results of the quantitative model for the United States (columns 3 to 6) and Germany (columns 7 to 10). It shows the value of the occupational shares (first panel) and mean earnings (second panel) in each of the 3 occupations considered (the 12 occupations grouped in 3 groups according to their level of risk): safe (S), medium (M) and risky (R) groups. The values of columns 3 and 7 refer to the baseline case. Columns 4 and 8 refer to the counterfactual exercise in which each country has the tax policy of the other: Taxes GER is the case of the United States with the tax code of Germany, and Taxes USA is the case of Germany with the tax code of the United States. Columns 5 and 9 refer to the counterfactual exercise in which each country has the earnings shocks of the other-specifically, the standard deviation of the permanent shocks. Shocks GER is the case of the United States with the shocks of Germany, and Shocks USA is the case of Germany with the shocks of the United States. Columns 6 and 10 , labeled as "No $\theta$ ", refer to the counterfactual exercise in which workers are ex ante homogeneous. The first panel present the levels and the second the change with respect to the baseline case. Occ, occupation. 
Table 8: Welfare Gains Relative to Baseline

United States

\begin{tabular}{lccc} 
& Taxes GER & Shocks GER & No $\theta$ \\
\cline { 2 - 4 }$\%$ Welfare from baseline & 2.55 & 3.73 & 1.60 \\
\hline & & \multicolumn{3}{c}{ Germany } \\
\cline { 2 - 4 }$\%$ Welfare from baseline & -4.55 & -9.09 & No $\theta$ \\
& & & 1.31 \\
\hline
\end{tabular}

Note: The table presents the welfare calculations using the quantitative model for the United States (first panel) and Germany (second panel). It shows the uniform percentage change in consumption, at each date and in each event, needed to make a household indifferent between being born into the baseline economy and being born into each of counterfactual economies. Taxes USA (second column of first panel) is the case of Germany with the tax code of the United States. Taxes GER (second column of second panel) is the case of the United States with the tax code of Germany. Shocks USA is the case of Germany with the shocks of the United States (third column of first panel). Shocks GER is the case of the United States with the shocks of Germany (third column of second panel). The column labeled as "No $\theta$ " refers to the counterfactual exercises in which workers are ex ante homogeneous.

Table 9: Logit Regression: Model-Simulated Panel

\begin{tabular}{lccccc}
\hline & \multicolumn{2}{c}{ United States } & & \multicolumn{2}{c}{ Germany } \\
\cline { 2 - 3 } \cline { 5 - 6 } \cline { 5 - 6 } & Baseline & Taxes & & Baseline & Taxes \\
& & GER & & -0.056 & USA \\
\hline$u^{-}$ & -0.689 & -0.812 & & -0.042 \\
Age & $-31.805 \times 10^{-4}$ & $-47.194 \times 10^{-4}$ & $-2.586 \times 10^{-4}$ & $-2.350 \times 10^{-4}$ \\
Age & $0.410 \times 10^{-4}$ & $0.841 \times 10^{-4}$ & & $0.006 \times 10^{-4}$ & $0.016 \times 10^{-4}$ \\
\hline
\end{tabular}

Note: The table displays the results of fitting a logit model to the occupation-switching decision on the negative of the earnings residuals $\left(u^{-}=\min \{u, 0\}\right)$, age, age squared, and occupational dummies (coefficients not shown). Baseline (columns 2 and 4) refers to the baseline economy. Taxes GER (column 3) is the case of the United States with the tax code of Germany, and Taxes USA (column 5) is the case of Germany with the tax code of the United States. 


\section{Appendix}

\section{Data and Sample Selection}

The main data sources are U.S. Panel Study of Income Dynamics (PSID) and the German Socio-Economic Panel (SOEP) (see Schupp, Kroh, Goebel, Bartsch, Giesselmann, Grabka, Krause, Liebau, Richter, Schmitt, Schnitzlein, Peter, and Tucci (2013)) provided by the Cross-National Equivalent File (CNEF) at Ohio State University (see Frick, Jenkings, Lillard, Lipps, and Wooden (2007)). The CNEF defines a set of variables of these data sets in a consistent way so the data sets are comparable. $^{31}$

For the PSID we use the data from 1981 through 2007, whereas for the SOEP we use the data from 1984 through 2012. Our sample selection procedure can be summarized as follows:

- The analysis is restricted to individuals between the ages of 26 and 60 years.

- We eliminate individuals who are not employed and those with zero earnings and zero hours of work.

- We eliminate individuals for for whom the information on sex, marital status, and education is missing.

- The analysis is restricted to individuals who are employed and report annual work hours of more than 1040 and less than 5110.

- We use earnings in real terms that are obtained using a consumer price index deflator for the United States and Germany. For the United States we eliminate those with earnings per hours less than 1 and more than 300 (in 1983 dollars). For the German data we eliminate those whose earnings per hour are less than 8.5 euros and more than 572 (in 2010 euros).

\footnotetext{
${ }^{31}$ The CNEF provides data for other countries as well; some are publicly available at https://cnef.ehe.osu.edu/data/ (PSID), while for other countries (i.e., SOEP) there are additional steps to follow to obtain the data.
} 
- The analysis is restricted to individuals with at least 8 consecutive periods of data.

- We eliminate individuals for whom the industry or occupation classification is missing.

- For the United States, the CNEF data on occupations are provided following the ISCO-68 classification of the International Labor Organization (ILO). The SOEP data on occupations are provided following the 4-digit ISCO-88 classification, a revision of the ISCO-68 coding made by the ILO. The CNEF provides the conversion of occupations from the ISCO-88 coding to the ISCO68 coding to make the two countries comparable. The CNEF provides data on 83 different occupations and the categories correspond to either 2-specific categories or sub groups of the ISCO68. We further group occupations because after all our restrictions are imposed in the sample there are very few workers in some occupations. We group them by closely following the criteria of ISCO-68 to group occupations according to their similarities in the skills required to perform them. The ISCO-68 major groups are 9; in our case we have 12 occupational groups as specified in Table 6. We eliminated soldiers; farmers, agricultural and animal husbandry workers; forestry workers and fishermen; hunters and related workers.

Table A.1: Occupation Classification

\begin{tabular}{ll}
\hline Occupation & CNEF Occupations \\
\hline & Physical scientists and related technicians \\
& Architects, engineers and related technicians \\
& Aircraft and ships' officers \\
& Life scientists and related technicians \\
& Statisticians, mathematicians, systems analysts and related technicians \\
& Economists \\
\hline Athletes, Artists, Religion & Accountants \\
& Jurists \\
& Workers in religion \\
& Authors, journalists and related writers \\
& Sculptors, painters, photographers and related creative artists \\
& Composers and performing artists \\
& Athletes, sportsmen and related workers \\
& Professional, technical and related workers not elsewhere classified \\
\hline 3 Managerial Workers & Legislative officials and government administrators; managers \\
\hline & $\quad$ Continued on next page
\end{tabular}




\begin{tabular}{|c|c|}
\hline Occupation & CNEF Occupations \\
\hline \multirow{3}{*}{4 Clerical Workers } & Clerical supervisors \\
\hline & Government executive officials \\
\hline & Clerical and related workers not elsewhere classified \\
\hline \multirow{7}{*}{5 Administrative Workers } & Stenographers, typists and card- and tape-punching machine operators \\
\hline & Bookkeepers, cashiers and related workers \\
\hline & Computing machine operators \\
\hline & Transport and communications supervisors \\
\hline & Transport conductors \\
\hline & Mail distribution clerks \\
\hline & Telephone and telegraph operators \\
\hline \multirow{6}{*}{6 Sales Workers } & Managers (wholesale and retail trade) \\
\hline & Sales supervisors and buyers \\
\hline & Technical salesmen, commercial travellers and manufacturers' agents \\
\hline & Insurance, real estate, securities and business services salesmen and auctioneers \\
\hline & Salesmen, shop assistants and related workers \\
\hline & Sales workers not elsewhere classified \\
\hline \multirow{10}{*}{7 Service Workers } & Managers (catering and lodging services) \\
\hline & Housekeeping and related service supervisors \\
\hline & Cooks, waiters, bartenders and relaters workers \\
\hline & Maids and related housekeeping \\
\hline & Service workers not elsewhere classified \\
\hline & Building caretakers, charworkers, cleaners and related workers \\
\hline & Launderers, dry-cleaners and pressers \\
\hline & Hairdressers, barbers, beauticians and related workers \\
\hline & Protective service workers \\
\hline & Service workers not elsewhere classified \\
\hline 8 Teachers & Teachers \\
\hline 9 Medical Workers & Medical, dental, veterinary and related workers \\
\hline \multirow{16}{*}{10 Manufacturing Workers } & Production supervisors and general foremen \\
\hline & Miners, quarrymen, well drillers and related workers \\
\hline & Metal processers \\
\hline & Wood preparation workers and paper makers \\
\hline & Chemical processers and related workers \\
\hline & Spinners, weavers, knitters, dyers and related workers \\
\hline & Food and beverage processers \\
\hline & Tailors, dressmakers, sewers, upholsterers and related workers \\
\hline & Shoemakers and Leather Goods Makers; Cabinetmakers and Related Woodworkers \\
\hline & Stone Cutters and Carvers; Blacksmiths, Toolmakers and Machine-Tool Operators \\
\hline & Machinery Fitters, Machine Assemblers and Precision Instrument Makers (except Electrical) \\
\hline & Electrical Fitters and Related Electrical and Electronics Workers \\
\hline & Broadcasting Station and Sound Equipment Operators and Cinema Projectionists \\
\hline & Plumbers, Welders, Sheet Metal and Structural Metal Preparers and Erectors \\
\hline & Jewellry and Precious Metal Workers \\
\hline & Glass Formers, Potters and Related Workers \\
\hline \multirow{7}{*}{12 Constructors, Painters, Transportation } & Printers and Related Workers; Painters \\
\hline & Production and Related Workers Not Elsewhere Classified \\
\hline & Bricklayers, Carpenters and Other Construction Workers \\
\hline & Stationary Engine and Related Equipment Operators \\
\hline & Material-Handling and Related Equipment Operators, Dockers and Freight Handlers \\
\hline & Transport Equipment Operators \\
\hline & Labourers Not Elsewhere Classified \\
\hline
\end{tabular}




\section{Additional Results}

In this section we report results for a set of alternative regressions for the logit model proposed in Section 2.4. The purpose is to assess the sensitivity of the relationship between occupational mobility to the earnings shocks experienced.

Table ?? report the results for both countries. The columns Add. Controls show the coefficients when additional controls are added to the regression. Specifically, age and its square. The columns Total Earnings show the coefficients when the realization of the shocks, $u^{-}$, are obtained from a regression with total earnings instead of earnings per hour (i.e. the baseline case). The signs and magnitudes of the coefficients confirms the similarity in the reaction of U.S. and German workers to earnings shocks.

Table A.2: Logit Regression: United States vs. Germany

\begin{tabular}{cccccc}
\hline & \multicolumn{2}{c}{ United States } & & \multicolumn{2}{c}{ Germany } \\
& Total Earnings & Add. Controls & & Total Earnings & Add. Controls \\
\cline { 2 - 3 }$u^{-}$ & -0.039 & -0.032 & & -0.041 & -0.022 \\
Age & $(0.010)$ & $(0.010)$ & & $(0.004)$ & $(0.005)$ \\
& & $-8.076 \times 10^{-3}$ & & $-0.466 \times 10^{-3}$ \\
Age $^{2}$ & & $\left(2.194 \times 10^{-3}\right)$ & & $\left(4.550 \times 10^{-3}\right)$ \\
& & $0.075 \times 10^{-3}$ & & $-0.005 \times 10^{-3}$ \\
& & $\left(0.027 \times 10^{-3}\right)$ & & $\left(0.011 \times 10^{-3}\right)$ \\
\hline
\end{tabular}

Note: The table displays the results of running a logit regression of the occupation switching decision on the negative of the earnings residuals $\left(u^{-1}=\min \{u, 0\}\right)$ and on a set of additional controls (Add. Controls) age, age squared, occupation dummies, and education dummies. For this second specification the table displays only the coefficients of age and age squared. The first two columns show results for the PSID and the last two columns show results for the SOEP.

\section{Model Computation}

Given a vector of parameters, the model's solution involves two steps. Finding occupation-decision policies and computing equilibrium wages $\left\{w_{j}\right\}_{j=1}^{3}$ for the three occupations.

- Occupation-decision policies: Despite the multi-armed bandit structure of the worker's problem, standard solutions ${ }^{32}$ for this type of problem can not

\footnotetext{
${ }^{32}$ This solution takes the form of what is known as a Gittins index. See Whittle (1982) for a textbook exposition of scheduling problems.
} 
be applied in our framework. The reason is the presence of general human capital introduces dependence across arms. In other words, the outcome in a prospective occupation depends on the histories of shocks the worker receives in the current occupation. ${ }^{33}$ Instead, we obtain the occupation-decision rules iterating directly on a worker's value function. However, to solve the problem of the worker, we do not directly use the equations described in the text. It is convenient to re-scale all variables by dividing them by the (aftertax) general level of human capital $\left(e^{z+\epsilon_{j}}\right)^{1-\phi_{1}}$. After that transformation the optimal choice of an occupation can be rewritten as,

$$
\tilde{W}_{s}\left(\Omega_{s}, \epsilon, j\right)=\max \left\{\tilde{V}_{s}\left(\Omega_{s}, \epsilon, j\right),\left\{\tilde{V}_{s}\left(\Omega_{s}, j^{\prime}\right)\right\}_{j^{\prime} \neq j}\right\}
$$

The value of staying - the analog to (15) is,

$$
\begin{gathered}
\tilde{V}_{s}\left(\Omega_{s}, \epsilon, j\right)=e^{(1-\gamma)\left(1-\phi_{1}\right) \epsilon}\left\{u(\tilde{c})+\beta \int \tilde{W}_{s+1}\left(\Omega_{s+1}, \epsilon^{\prime}, j\right) d F_{j}(\epsilon)\right\} \text {, s.to } \\
\tilde{c}=\phi_{0}\left(w_{j} e^{\theta_{j}}\right)^{1-\phi_{1}}
\end{gathered}
$$

The value of an alternative occupation not previously tried can be rewritten as:

$$
\tilde{V}_{s}\left(\Omega_{s}, j^{\prime}\right)=\int \tilde{V}_{s}\left(\Omega_{s}, \theta, \epsilon, j^{\prime}\right) d G_{j^{\prime}}(\theta) d F_{j^{\prime}}(\epsilon)
$$

Conditional on a particular $\theta$ and $\epsilon$, the value of the alternative occupation is that attained by adding the utility flow from earnings plus the continuation value:

$$
\begin{gathered}
\tilde{V}_{s}\left(\Omega_{s}, \theta_{j^{\prime}}, \epsilon, j^{\prime}\right)=e^{(1-\gamma)\left(1-\phi_{1}\right) \epsilon}\left\{u(\tilde{c})+\beta \int \tilde{W}_{s+1}\left(\Omega_{s+1}, \epsilon^{\prime}, j^{\prime}\right) d F_{j^{\prime}}\left(\epsilon^{\prime}\right)\right\} \text {, s.to } \\
\tilde{c}=\phi_{0}\left(w_{j^{\prime}} e^{\theta_{j^{\prime}}} e^{-c(s, \kappa)}\right)^{1-\phi_{1}}
\end{gathered}
$$

\footnotetext{
${ }^{33}$ The presence of age-dependent occupational moving costs is also an element that precludes
} the use of a Gittins index. 
Finding the transformed value of an occupation involves eliminating the uncertainty with respect to $\theta$ :

$$
\tilde{V}_{s}\left(\Omega_{s}, j^{\prime}\right)=\int \tilde{V}_{s}\left(\Omega_{s}, \theta, \epsilon, j^{\prime}\right) d F_{j^{\prime}}(\epsilon) .
$$

To simplify the calculations we discretize the distributions of shocks $\left\{\epsilon_{j}\right\}_{j=1}^{3}$ and occupation-specific abilities $\left\{\theta_{j}\right\}_{j=1}^{3}$. Discretizing involves choosing the number of points that constitute the support of $\epsilon$ or $\theta$ and their probability masses. Let $N_{\epsilon}$ and $N_{\theta}$ be the number of points used to approximate the distributions of $\epsilon$ and $\theta$. We use the same dimension for all occupations. For $j \in\{1,2,3\}$, the support of $\hat{\epsilon}_{j}$, the discretized $\epsilon_{j}$, is $\left\{\epsilon_{1, j}, \ldots, \epsilon_{N_{\epsilon}, j}\right\}$. The probability of sampling $\epsilon_{n, j}$ is $p_{n, j}$ for $n=1, \ldots, N_{\epsilon}$. Likewise, for $j \in\{1,2,3\}$, the support of $\hat{\theta}_{j}$, the discretized $\theta_{j}$, is $\left\{\theta_{1, j}, \ldots, \theta_{N_{\theta}, j}\right\}$. The probability of sampling $\theta_{n, j}$ is $q_{n, j}$ for $n=1, \ldots, N_{\theta}$. Also, $\sum_{n=1}^{N_{\epsilon}} p_{n, j}=1$ and $\sum_{n=1}^{N_{\theta}} q_{n, j}=1$ for any $j$. In the paper we set $N_{\epsilon}=6$ and $N_{\theta}=4$.

With the discretization we compute value functions only at the set of points that make up the support for $\epsilon$ and $\theta$. An expected value function is a probability-weighted sum of value functions. For example, the discrete approximation to the left-hand-side of (31) is,

$$
\tilde{V}_{S}\left(\Omega_{s}, j^{\prime}\right) \approx \sum_{n=1}^{N_{\epsilon}} p_{n, j} \tilde{V}_{s}\left(\Omega_{s}, \theta, \epsilon_{n, j^{\prime}}, j^{\prime}\right)
$$

Finally, the set $\Omega_{s}$ for any give age $s$ comprises two elements: (a) a vector $\left\{\chi_{j}\right\}$ where $\chi_{j}=1$ if the occupation has been visited at any age up to (and including) $s-1$, (b) the vector of individual- and occupation-specific ability values $\left\{\theta_{j}\right\}_{j=1}^{3}$.

Starting with the guess $\tilde{W}_{S+1}=0$ for any value of the state vector, we compute all value functions for all ages and values of the state vector, by backward induction.

- Equilibrium: To find the set of market-clearing wages we use the following procedure: 
1. Guess a set of wages $\left\{w_{j}^{(m)}\right\}_{j=1}^{3}$.

2. Calculate workers' value functions according to the backward induction procedure described earlier.

3. Simulate the lives of a large number $P$ of agents.

4. Compute efficiency units of labor in each occupation $j: N_{j}$.

5. Compute a new set of wages $\left\{w_{j}^{(m+1)}\right\}_{j=1}^{3}$.

The procedure stops when $\left\|\left\{w_{j}^{(m)}\right\}_{j=1}^{3}-\left\{w_{j}^{(m+1)}\right\}_{j=1}^{3}\right\| \approx 0$.

With the results from Step 2, it is fairly simple to perform Step 3. Once the value functions for workers have been computed, we can draw values for the random variables and record workers' occupational decisions and associated productivity levels. With $P$ agents ${ }^{34}$ each living for $S$ years, let $L$ be the total number of individual-age observations: $L=P \times S=L_{1}+L_{2}+L_{3}$, where $L_{j}$ is the number of individual-age observations in occupation $j$. Then,

$$
N_{j}=\frac{1}{L_{j}} \sum_{l=1}^{L_{j}} e^{z_{l}} e^{\theta_{j, l}} e^{-c_{l}},
$$

where $e^{-c_{l}}$ is equal to the switching cost for individual-age observation $l, e^{z_{l}}$ is her general human capital level, and $e^{\theta_{j, l}}$ is her occupation- $j$ ability. 